NBER WORKING PAPER SERIES

\title{
AGGREGATE ADVERTISING EXPENDITURE IN THE U.S. ECONOMY: WHAT'S UP? IS IT REAL?
}

\author{
Alvin Silk \\ Ernst R. Berndt \\ Working Paper 28161 \\ http://www.nber.org/papers/w28161 \\ NATIONAL BUREAU OF ECONOMIC RESEARCH \\ 1050 Massachusetts Avenue \\ Cambridge, MA 02138 \\ December 2020
}

This paper is dedicated to the memory of Robert J. Coen, Senior Vice-President, Interpublic Group. Mr. Coen was acknowledged to be Madison Avenue's "Chief Forecaster" and admired as the dedicated curator of McCann-Erickson's historical database on U.S. advertising expenditures. Mr. Coen passed away on November 18, 2016. This research was supported by the Division of Research, Harvard Business School and the MIT Sloan School of Management, but has not been otherwise sponsored. We thank Michael Leszega and Vincent Letang for assistance in accessing Magna Global's data. We also acknowledge very useful and constructive communications with Professors W. Erwin Diewert (University of British Columbia) and Kevin J. Fox (University of New South Wales), and with Kathleen Frawley and Sarah Eian of the U.S. Bureau of Labor Statistics, Producer Price Index program. However, the authors are responsible for any errors and omissions. The views expressed herein are those of the authors and do not necessarily reflect the views of the National Bureau of Economic Research.

NBER working papers are circulated for discussion and comment purposes. They have not been peer-reviewed or been subject to the review by the NBER Board of Directors that accompanies official NBER publications.

(C) 2020 by Alvin Silk and Ernst R. Berndt. All rights reserved. Short sections of text, not to exceed two paragraphs, may be quoted without explicit permission provided that full credit, including $(\odot$ notice, is given to the source. 
Aggregate Advertising Expenditure in the U.S. Economy: What's Up? Is It Real?

Alvin Silk and Ernst R. Berndt

NBER Working Paper No. 28161

December 2020

JEL No. L16,L86,M37

\begin{abstract}
The two components of the advertising industry - the creative sector that develops and produces messages, and the communications sector that transmits messages via various media - have each been greatly affected by advances in creative design and communications technologies. As the media composition of advertising has changed in the last century for both local and national advertising - from newspapers, outdoor and radio advertising to network and cable television, and most recently to internet and digital media - so too has been transformed the very concept of advertising, its functionality and its measurement.
\end{abstract}

We compare four sources of annual nominal U.S. aggregate advertising expenditure data - from the public sector Internal Revenue Service and the U.S. Census Bureau Survey of Service Industries, and the private sector McCann Erickson and Magna Global advertising agencies- that are available over various time periods. In nominal terms, we estimate the elasticity of advertising expenditures with respect to Gross Domestic Product, and find that this elasticity appears to have increased substantially beginning in the late 1990s - from about 1.4 to 1.9. The timing of this structural break coincides roughly with the decline of print, radio and network and cable television, and the dramatic increase in digital and internet-based advertising.

To understand the forces underlying this structural break in nominal advertising expenditures, data on media-specific advertising prices are needed, thereby converting nominal to real advertising. However, currently annual U.S. Bureau of Labor Statistics Producer Price Index data on digital and many other advertising media prices are only available beginning in 2010 . The availability of media-specific quality-constant price indexes would not only enable researchers to trace more completely the recent impact of digital and internet advertising, but would also facilitate contemporary and longstanding issues to be addressed surrounding the measurement of advertising effects, including how variations in the durability of response to advertising across media are related to inter-media price differentials, and why heterogeneity among firms and industries may arise with respect to the procyclicality of advertising policies.

\author{
Alvin Silk \\ Graduate School of Business Administration \\ Harvard University \\ Soldiers Field \\ Boston, MA 02163 \\ asilk@hbs.edu \\ Ernst R. Berndt \\ MIT Sloan School of Management \\ 100 Main Street, E62-533 \\ Cambridge, MA 02142 \\ and NBER \\ eberndt@mit.edu
}




\section{Introduction}

Appearing at an Interactive Advertising Bureau (IAB) conference in 2005, Bill Gates reportedly was asked "Why is online advertising growing so fast?" In his oft-quoted response, he proclaimed that "Well, when you think about it, the future of the advertising is the Internet." 1 Gates proved to be prescient in the sense that post-2005, total outlays for digital advertising in the U.S. continued to rise at double digit growth rates, with the exception of 2009, the year of the Great Recession. Paradoxically, early in 2014 an article appearing in Bloomberg News proclaimed that “Looking at data since the 1920's, the U.S. advertising industry has always been about 1 percent of U.S.GDP". The article further maintained that history revealed that new media (radio, television, and the Internet) followed a "predictable" growth pattern: five years of "rapid (but declining) growth rates," after which "growth rates steadied," "matching" that of the U.S. economy. Hence, the U.S. advertising is an industry where "the pie is not growing... The easiest way to make more money is to steal larger slices of the pie."

By 2016, digital advertising had supplanted television as the medium with the largest share of U.S. total advertising receipts earned by media suppliers. ${ }^{3}$ Nonetheless, later in that same year a report emanating from a Wall St. brokerage firm presented data indicating that total U.S. advertising as a percentage of GDP was declining. ${ }^{4}$ More recently, in 2019 it was reported that the "growth in the U.S. advertising market has been unable to maintain its historical trend of growing in lockstep with gross domestic product, equating to approximately $2 \%$ of GDP". ${ }^{5}$ Relating the dramatic growth in digital's market share to growth in the size of the total advertising market, Wieser recently observed that "Deceleration was always inevitable for one core reason: there is only so much growth to be had." 6

Together, these periodic reports and observations suggest that the rapid growth of digital advertising has occurred over a period during which the share of U.S. economic activity (as measured by GDP) represented by total advertising expenditures has been in decline, a development that, if substantiated, would represent a striking departure from what previously

\footnotetext{
${ }^{1}$ See Phillipson [2016].

${ }^{2}$ Chemi [2014]. Italics added.

${ }^{3}$ Letang and Leszega [2017], Magna Global [2015].

4 Juenger et al. [2016].

${ }^{5}$ Baine [2019], p. 4. Italics added.

${ }^{6}$ Wieser [2019], p. 1. Italics added.
} 
had been regarded a stable long-term proportion (Telser [1968]). It bears noting that over the period since the launch of digital media in 1996 through $2018^{7}$, the U.S. economy has experienced two full business cycles, one of eight months in 2001 and the Great Recession of 18 months in 2008-09. ${ }^{8}$ Moreover, the digital transformation has not only led to an extensive overhaul of the methods used to measure aggregate advertising industry spending, but also to an ongoing program of research and revision of the measurement of GDP, including the treatment of advertising in the U.S. system of national accounts and its representation/inclusion in GDP. ${ }^{9}$

The U.S. advertising industry is in the throes of change as it seeks to adapt to the farreaching, but still unfolding effects of the digital disruption that has already transformed not only the media habits (Coyle and Nakamura [2019]) and purchasing behavior of consumers (Goldfarb and Tucker [2019]) but also the distribution and advertising strategies firms pursue and how those activities are organized and managed (Burton [2008], Evans [2008],[2009]).

In light of these considerations, the fundamental question to be addressed here is: Does the U.S. advertising industry have a growth problem, a measurement problem, or both ${ }^{10}$ The paper is organized as follows. We begin in Section II with some historical background on the vertical structure of the U.S. advertising industry. Then in Section III we describe a patchwork of four time series we have assembled that measure nominal aggregate advertising spending by advertisers and the related revenues of two sectors who function as service providers to advertisers -- advertising agencies and media firms. In Section IV we set forth the analytic framework we employ relating nominal aggregate advertising expenditures to Gross Domestic Product. In Section $V$ we describe the time series and econometric methods used to analyze the four times series covering different but overlapping time periods between 1960 and 2018. In Section VI we detail our results and in Section VII we follow with a discussion of several implications of our findings. In Section VIII we briefly summarize our main conclusions.

\footnotetext{
${ }^{7}$ As noted in Internet Advertising Bureau [2019], p. 11.

${ }^{8}$ National Bureau of Economic Research [2016], p. 1.

${ }^{9}$ On this, see, for example, W. Erwin Diewert and Kevin J. Fox [2020].

${ }^{10}$ This framing of the issue was suggested by the title of the paper by Byrne, Fernald and Reinsdorf [2016].
} 


\section{Historical Background}

Estimates of the economic value or volume of advertising activity in the U.S. have long been recognized as vital information that not only serves as a basic indicator of the performance of an important sector of the domestic economy, but also represents a key input widely utilized by business, government, and academic organizations to support policy analysis, planning, and forecasting. Given the dynamics of the U.S. economy and the adaptive nature of advertising and marketing practices, the history of advertising is one of recurring life cycles of growth and decline coinciding with the introduction of a "new" medium that substitutes for (and/or complements) elements in the prior mix of media available to advertisers. ${ }^{11}$ Thus changing media technologies have led to discontinuities in existing time series that are revised or replaced by successor measures that may differ markedly from their predecessors in concept (e.g., how advertising is defined, by what methods and metrics its economic value is measured, and by the nature and sources of data collected), as well as with respect to the mix of media types and vehicles that advertisers employ in practice. ${ }^{12}$

In the course of formulating a program of research on the contribution of service industries to the U.S. economy, Griliches observed that: "To measure the output of any industry we need to know its total receipts and have adequate information to construct an appropriate price index for it". He further suggested that: "Rather than discussing definitions, it may be more useful to take an operational approach and to examine what are actually called services in the national accounts and related statistical sources." ${ }^{13}$ Interestingly, "advertising" was among the service industries he identified as deserving attention. In that same spirit and for the purposes at hand we turn to the operational definition of "advertising" that Borden [1944] proposed in his seminal study of the economics of advertising:

"Advertising includes those activities by which visual or oral messages are addressed to the public for the purposes of informing and influencing them to

\footnotetext{
${ }^{11}$ On the history of these developments, see Sherman [1900], Blank [1963], Borden [1944, Chapter III], Yang [1962, Chapter 1], Simon [1970, Appendix D] and the references cited therein.

${ }^{12}$ See Schultz [2016] for a recent discussion of the problems arising from "the lack of an acceptable definition of the 'field' of advertising". As Arrow et al. [1990] lamented in a different context, "It is very difficult to determine where to draw the line between advertising and other forms of selling and promotion" and "Even if one defines advertising narrowly as, say, media advertising it is still a heterogeneous commodity" (p.7).

${ }^{13}$ Griliches, "Introduction" in Griliches et al. [1992], p. 6. Italics added.
} 
either buy merchandise or services or to act or be inclined favorably toward ideas, institutions, or persons featured." 14

Borden went on to distinguish "advertising" from "publicity and other forms of propaganda" in two important respects: (i) advertising messages are identified with the advertiser either by "signature or oral statement"; and (ii) "advertising is a commercial transaction involving pay to publishers or broadcasters and others whose media are involved." 15

Taking Borden's definition as our point of departure, we posit that the total amount a firm expends on advertising is the sum of the costs incurred by engaging in two fundamental but distinct activities essential to an advertising campaign: the costs of developing and producing messages, plus the costs of delivering those commercial messages to the audiences of media vehicles that include members of the advertiser's target market segments.

As we discuss below, the structure of the U.S. advertising industry distinguishes these two distinct activities, although that structure has evolved over time.

\section{The U.S. Advertising Industry: Vertical Structure and Aggregate Measures of Spending}

\section{III.1 Vertical Relations}

Figure 1 depicts the vertical structure of the advertising industry as consisting of advertisers and audience connected through two intermediary sectors: (i) independent firms who provide an array of advertising and marketing services (A\&MS) related to the development and production of marketing communication campaigns, and (ii) suppliers of media space/time

\{Insert Figure 1 Somewhere Near Here)

by which advertising campaigns are displayed to target audiences. Solid vertical lines connecting the three adjacent layers or sectors reflect the traditional (and still dominant) structure featuring intermediaries (e.g., full-service advertising agencies and media suppliers). In addition, the existence of two modes of vertical integration is recognized: (i) forward integration by advertisers who internalize one or more advertising and marketing services (Silk and Stiglin [2016]) and (ii) backward integration by media suppliers who internalize one or more advertising

${ }^{14}$ Borden [1944], p. 17.

${ }^{15} / d$. 
and marketing services (Gupta and David [2019]). Each mode is represented by a dashed line connecting advertising and media suppliers.

For each of the three levels, one or more time series data sources are listed within the box corresponding to that level: Firm Advertising Expenditures (IRS, MCE); A\&MS Service Provider Revenues (SAS8) ; and Media Supplier Advertising Revenue (MG8), which we now describe.

\section{III.2 Measures}

We analyze alternative time series as indicators of the economic value of the advertising-related activities associated with each of the three top levels of the structure represented in Figure 1: (a) the aggregate amounts firms expend on advertising campaigns (IRS and $M C E$ ) and the distribution of such outlays among downstream intermediaries in the form of revenues captured by suppliers of (b) advertising and marketing services for developing and producing advertising campaigns (SAS8) and of (c) media supplier revenues (MG8) from sales of time and space to display advertisers’ campaigns to reach target audiences.

\section{III.2.1 Internal Revenue Service Reports of Corporate Advertising Expenses (IRS)}

The Internal Revenue Service (IRS) reports estimates of advertising expenditures corporations claim in filing federal tax returns. To illustrate, for the tax year 2012, the IRS estimated that advertising spending by U.S. corporations amounted to $\$ 274.504$ billion. ${ }^{16}$ That estimate was based on a stratified sample of more than 110,004 unaudited returns selected from 5.841 million tax returns filed by active corporations for the tax year 2012. Note that "tax years" can differ from "calendar years," i.e., the Tax Year 2012 includes accounting periods ending July 2012 through June 2013. The IRS data have been widely used in advertising and economic research dating back to the seminal work of Yang [1962] and Telser [1964].

Certain limitations of the IRS data bear noting. First, the nature and composition of what are reported as "advertising" expenses may vary among corporations and is likely to include elements of consumer and trade promotion as well as media advertising. ${ }^{17}$ The IRS provides the following guidance as to what constitutes "advertising" according to the tax code: "This deduction for promotional activities, directed toward the sale of goods and services in the

\footnotetext{
${ }^{16}$ Internal Revenue Service [2012], Table 2, p. 35.

${ }^{17}$ Rogers and Tokle [1995].
} 
course of the business activity, is separately identified on the corporate income tax form. The statistics for this deduction for corporations also include amounts reported as cost of sales for corporations." 18

A second ambiguity was recognized by Comanor and Wilson ${ }^{19}$ who suggested that in the case of firms that fully or partially internalize advertising services, the cost of such operations are unlikely be included as "advertising expense" in corporate tax returns. Third, by definition, advertising expenditures by unincorporated business are excluded.

Given the size and scope of firms filing Federal tax returns, the length of the time series of annual estimates of aggregate advertising expenditures, and its public availability, the IRS data may serve as a standard of comparison for other measures. In some cases, it may approximate a lower limit on the total U.S. advertising spending, for several reasons. Estimates of advertising spending are frequently based on samples of the "leading" or "top" advertisers and thus underestimate total expenditures by excluding the fraction of the population of advertisers that falls short of the cutoff size ranking. A quite different selection bias affects advertising expenditure data that rely on public archival sources such as $10 \mathrm{~K}$ reports filed with the Securities and Exchange Commission by U.S. corporations. It has been noted that "a majority of publicly traded firms are excluded from published studies of marketing's value relevance because those firms do not disclose their advertising expenditures" 20 .

Finally, as will be discussed further below, the IRS advertising time series can be used in making assessments akin to psychometric concepts of "convergent" and "discriminant" validity of alternative measures of aggregate advertising expenditures. ${ }^{21}$

\section{III.2.2 McCann-Erickson Estimates of Expenditures for Media Advertising (MCE)}

For more than five decades, the time series produced by McCann-Erickson (forerunner of the holding company, Interpublic Group -- IPG) on advertising expenditures has been recognized as the advertising industry's authoritative source of data on aggregate advertising spending in the U.S. economy. These data were published annually in Advertising Age and the

\footnotetext{
${ }_{18}$ Internal Revenue Service, [1962], Statistics of Income 1960-61: U.S. Business Tax Returns, Washington DC: U.S. Treasury Department, Internal Revenue Service, Publication No. 438 (6-620, p. 6.

${ }^{19}$ Comanor and Wilson [1974], p. 5.

${ }^{20}$ McCallister et al. [2016], p. 208. See Shi et al. [2017] for an analysis of a 1994 reporting rule that made disclosure of advertising expenditures by public firms voluntary in the U.S.

${ }^{21}$ On this, see Campbell and Fiske [1959].
} 
Statistical Abstract of the United States. The data series encompassed a broad set of eleven "measured media" (e.g., direct mail, newspapers, magazines, out-of-home, radio, broadcast television, cable television, yellow pages, business publications, internet, and "miscellaneous"). Each medium was further classified as "national" vs. "local," in order to capture differences in the geographical scope of the audience reached by available media options. Whereas three media (business magazines, direct mail, and the internet) were treated as exclusively "national," in each of the other eight media both "national" and" local" sub-categories were recognized.

The amount expended in a medium can be envisaged as the product of a volume or quantity (measured in units of "exposures" that reflect the size of the cumulative audience reached over time by a series of ads appearing in a media vehicle) and the price per unit of exposure in that vehicle. Both exposure levels and unit prices may differ not only among vehicles within a given medium and across media, but may also vary over time.

The MCE estimates of media advertising expenditures were developed from an eclectic body of "volume" data obtained from media monitoring services, trade associations, and proprietary sources. The resulting series represented estimates of media "billings" (expenditures in current dollars), typically based on information about current "list" prices (such as those stated on media vendors' "rate cards") rather than actual "transaction" prices that reflected volume and other discounts negotiated by media buyers and sellers.

For much of the post-World War period in the U.S., agencies were compensated for supplying clients with a bundle of services by a fixed rate of commissions (typically 15 percent) on the amount clients were billed for media services purchased by an advertising agency on their behalf. Over time and in response to client demands, agencies gradually adopted a policy of unbundling their services, with agency compensation shifting from reliance on media commissions to fee-for-service arrangements based on labor charges for agency personnel assigned to the client's account. ${ }^{22}$ As a result of those developments, the extent to which estimates of media billings captured the actual amounts client paid to agencies and other intermediaries for creating and producing messages, as distinct from payments to media suppliers to purchase time and space, became an issue of concern throughout the industry.

\footnotetext{
${ }^{22}$ For discussion, see Arzaghi et al. [2012].
} 
With "bundling" so prevalent, it was challenging for ad agencies to separate the two revenue sources. ${ }^{23}$

A major changeover occurred in 2009 when the Interpublic Group (IPG) announced it was discontinuing compiling and publishing the McCann-Ericson advertising media spending series. Through its media services unit, Magna Global, it launched a new set of media spending estimates designed to more accurately capture shifts in media spending by advertisers, especially those related to the rapid growth of digital media. ${ }^{24}$

\section{III.2.3 Magna Global Estimates of Media Supplier Advertising Revenues (MG8)}

The new Magna Global measures represented a fundamental departure for the McCann-Ericson series it replaced with respect to scope and granularity of media included, the nature and sources of primary data, as well as the estimation methodology. To facilitate understanding of the new measurement system, Magna Global released a detailed description of the structure of the measures and how they were constructed, as well as going back in time and calculating estimates using the new methodology for the period 1980 onward. ${ }^{25}$ Whereas the McCann-Erickson measures were described as the product of a "bottoms up" approach, Magna Global adopted instead a "top down" orientation in developing a new set of measures that focused on assembling data on the revenues from advertising reported by media suppliers. ${ }^{26}$

Magna Global developed an elaborate classification scheme that it employs in reporting estimates of advertising revenues earned by media suppliers. Figure $2 \mathrm{a}$ shows the post-2009 hierarchical structure of Magna Global's media typology. Media are first classified as "Direct," "National" or "Local." Within each of those three basic media domains are a set of subcategories that includes seven "core" media (Digital, Directories, Magazines, Newspapers. Radio, Television, and Out-of-Home) plus direct mail that together comprise the total, which hereafter we designate as MG8\$.

(Insert Figures $2 a$ and $2 b$ Somewhere Near Here)

\footnotetext{
${ }^{23}$ See Silk [2012] and Silk and King [2013] for details.

${ }^{24}$ For details, see Mandese [2007], [2009a,b].

${ }^{25}$ Magna Global [2015].

${ }^{26}$ Mandese [2009a].
} 
Of particular significance was the introduction of the "Digital" category utilizing the Internet Advertising Bureau format typology. ${ }^{27}$ Moreover, Magna Glob al further sub-divided each format according to the device where the advertising appeared: desktop vs. mobile. The resulting hierarchical structure in presented in Figure $2 b$.

The structure depicted in Figure 2a reflects factors similar to those that Silk, Klein, and Berndt [2001] identified as being related to patterns of intermedia substitutability and complementarity observable from analyses of traditional media prices and expenditure data: "addressability," "contractual flexibility," and "audience control." Goldfarb [2014] has argued that the capacity for precise targeting is the principal advantage digital advertising holds over advertising in traditional media. Digital advertising is further advantaged with respect to facilitating greater audience control over exposure by virtue of being interactive and conveniently available as demanded. Finally, digital media buying is a highly automated process that offers advertisers considerable contractual flexibility as indicated by the recent IAB report that programmatic buying now accounts for $80 \%$ of all display advertising. ${ }^{28}$

\section{III.2.4 Census Bureau Services Annual Survey Estimate of Advertising and Marketing Service Supplier Receipts (SAS8)}

Over time, an ever-expanding array of services have become available to support the development and production of advertising programs. Silk and King [2013] introduced a set of nine sectors that collectively represented a useful operational definition of the advertising and marketing services (A\&MS) industry. Each of the nine sectors was identified in the North American Industrial Classification System (NAICS) adopted by the Census Bureau in 1997. Sector definitions and their corresponding NAICS codes are presented in Table A1 in the Appendix. For the first eight sectors listed there (Advertising Agencies, Public Relations Agencies, Media Buying, Outdoor Advertising, Direct Mail Advertising, Advertising Materials, Other Services Distribution, and Marketing Research and Public Opinion Polling) annual estimates of receipts are available from the Census Bureau's Service Annual Surveys (SAS8). In the case of the ninth sector, Marketing Consulting, revenue data are available only for the years when the Census Bureau conducts its quinquennial Economic Census (e.g., 1992, 1997,...,2012, 2017).

\footnotetext{
${ }^{27}$ Internet Advertising Bureau [2019].

28 Internet Advertising Bureau [2020], p. 6.
} 


\section{III.3 Trends in Sector Revenues and the Advertising Share of GDP}

Summary statistics for the three alternative time series of output of the U.S. advertising industry discussed above along with those for nominal GDP are presented in Appendix Tables 2a and $2 \mathrm{~b}$. In order to highlight certain trends and phenomena that we address in the econometric analyses that follows, below and in the Appendix we present several graphs that facilitate comparisons among the four measures of advertising output and GDP over time, measured in billions of dollars: IRS\$BN, MCE\$BN, MG8\$BN, and Census Service Annual Surveys, SAS8\$BN.

We begin with Figure 3 that traces the level of total outlays for our four output measures over the period 1960-2018. Several trends are particularly noteworthy. First, it is evident that the IRS\$BN and MCE\$BN series that purport to measure total advertising spending by firms (the top two series in Figure 3) are highly correlated over the period 1960-2007 $(r=0.998)$. Second, the gap between the levels of media suppliers' advertising revenues (MG8\$BN) and MCE\$BN (from which it was derived) grew over time from 1980, the first

(Insert Figure 3 Somewhere Near Here)

period for which MG8\$BN was estimated, through the peak in 2007. Following the trough of the Great Recession in 2009, it appears that the absolute differential between media suppliers' receipts (MG8\$BN) and total advertising outlays firms (as measured by the IRS\$BN series) - the two middle series in Figure 3 -- remained relatively constant. Finally, over the 2001-2018 period for which revenues for both the media supplier sector (MG8\$BN) and advertising agency and related services sectors (SAS8\$BN) are available, the former (SAS8\$BN) grew in relation to the latter (MG8\$BN); the ratio of SAS8\$BN to MG8\$BN rose from about 0.40 in 2001 to 0.57 in 2018. To place these advertising expenditures in the context of nominal GDP, in Appendix Figure 1 we plot the three advertising expenditure series as a share of nominal GDP for 19602018.

In Appendix Figure $\mathbf{2}$ we compare the nominal annual growth rates (percent changes) of IRS\$BN, MCE\$BN and MG8\$BN with that for nominal GDP (RGDPNG) over the period 19612018. Overall, it is apparent that the peaks and troughs of the three advertising series mirror the National Bureau of Economic Research dating of U.S. business cycle expansions and contractions. ${ }^{29}$ As well, the movements of the three advertising series also tend to coincide with the cyclical changes in nominal GDP. Of particular interest is that the annual growth rates

\footnotetext{
${ }^{29}$ National Bureau of Economic Research [2016].
} 
appear to have risen from 1961 to the mid-1970's, followed by a period of slow/stable growth rates. We examine this pattern further below in our analyses of the advertising share in GDP.

Figures 4 and 5 plot 1980-2018 changes in the shares of each of the eight media comprising Magna Global's measure (MG8\$BN) of the total receipts media suppliers generate from sales of time and space purchased to display ad messages. Comparable time series measures of advertising receipts are not available for MCE8\$BN, IRS\$BN, and SAS8\$BN. The three striking trends in these two figures from MG8\$BN involve the remarkable increase in the Digital share ZSHDG since 1996 (Figure 4), the coincident dramatic decline in the Newspaper share ZSHNWP (Figure 5), and the initial increase in the Television share ZSHTV that peaked in 2014, and then fell sharply (Figure 4). Figure 4 plots shares for four media based on MG8\$BN, labelled (somewhat arbitrarily as "Major"). The digital time series ZSHDG begins in 1996 and within only two decades supplanted Television (ZSHTV) as the dominant medium in 2016. Interestingly, whereas Digital's ZSHDIR share reached almost 48 percent in 2018, TV's ZSHTV

(Insert Figure 4 Somewhere Near Here)

share was 28 per cent at the time of Digital's entry in 1996, reached its peak share of almost 35 per cent in 2014 and since then has declined to 28 per cent in 2018. Direct Mail ZSHDM has lost a third of the 12 per cent share it realized in 1980, while Directories' ZSHDIR share has plummeted from a peak of almost nine per cent in 1991 to less than one per cent in 2018.

Turning to "minor" media in Figure 5, we observe that the Newspaper share (ZSHNWP) has undergone the most dramatic decline, falling from 37 per cent in 1980 to just four per cent (Insert Figure 5 Somewhere Near Here) in 2018. The Magazine share (ZSHMAG) also dropped precipitously from 12 to three per cent. Radio's 2018 ZSHRD share of six per cent was only roughly half of its peak share of 12 per cent in 2002. In contrast, Out-of-Home's ZSHOH share has gained roughly a share point over the 19802018 period. Note that these advertising media shares are all based on MG8\$BN data on media receipts, and that comparable time series receipts data are not available for MCE8\$BN, IRS\$BN and SASB\$BN.

Lastly, in Appendix Figures 1 and 3 we plot the nominal advertising shares in total nominal GDP (Appendix Figure 1)) and in Private Sector nominal GDP (Appendix Figure 3). In his recent analyses of advertising and the business cycle, Hall ([2012], [2014]) has focused on the advertising share in private sector GDP, noting that public sector spending on advertising is 
limited. ${ }^{30}$ A comparison of Appendix Figure 1 and Appendix Figure 3 indicates that advertising's share of nominal private sector GDP is greater than that for nominal total GDP, but the pattern of cyclical variations is similar. Our 1960-2007 time series for IRS\$BN and MCE\$BN shares of total GDP both begin in 1960, the peak year of an eight month recession and encompasses several subsequent cycles. The series both peak in in 2000 (shares of 2.3 percent and 2.4 percent for MCE\$BN and IRS\$BN in total GDP, respectively), the year prior to the onslaught of the Great Recession. However, in the ensuing periods which our time series covers (through 2007 and 2014 for MCE\$BN and IRS\$BN, respectively), the nominal advertising share of total GDP continues to decrease, in each case dropping below two per cent. A similar pattern appears to hold for MG8\$BN for the more abbreviated 1980-2018 time series. The question that naturally arises is: Is this pattern real or illusionary? What phenomena can explain the apparent downturn?

To this point, we have examined nominal measures of advertising spending and receipts, by media type and in the aggregate, and trends in the aggregate advertising/GDP ratio over time (Appendix Figure 1). As we have seen, the most striking compositional phenomena are the remarkable increase in the digital advertising share since 1996, the coincident dramatic decline in the newspaper advertising share, and the alternating increase and then decrease in the television advertising share (Figures 4 and 5). To what extent have these compositional changes affected the aggregate advertising to GDP ratio, and more fundamentally, what are the factors driving media composition changes? Are media-specific prices, and the price of an advertising aggregate, impacting aggregate advertising spending and its composition?. Unfortunately, as we shall now see, research on these issues is currently severely handicapped by the absence of any publicly available data on digital and internet advertising prices and volumes, particularly in the first fifteen years following the launch of digital and internet advertising in 1996.

\section{III.4 Advertising Cost Indices}

The digital era is not the first time in modern advertising history when the historic and future growth and structure of the industry has been questioned. Such a set of circumstances arose in the late 1950's when Myers ([1958],[1962]) observed that U.S. advertising expenditures

\footnotetext{
${ }^{30}$ Kosar [2014] estimated that in fiscal year 2014, $\$ 893.5$ million was expended on advertising by the federal government.
} 
as a share of National Income had declined from a peak of more than four percent in the 1920's to 1.5 per cent in 1945 , then recovered in the post WWII era to just under three percent in 1957, still shy of the pre-Great Depression peak. Myers went on to point out that, among other things, "improved media efficiency permitted the 1977 advertising expenditure to purchase at least two-and-a-half times the exposure to advertising 'space and time' as did the 1929's expenditure" [1958, p. 370]. Blank [1963] claimed that advertising professionals and academics both subscribed to the view that "advertising expenditures have never regained the levels of relative importance that they achieved prior to 1930" ("the golden age of advertising"). He proceeded to suggest the possibility that this "anomaly" might be explained by "some error or bias in the underlying data" from which the conclusions had been drawn. ${ }^{31}$

In terms of private sector historical data availability, for many years the McCann Erickson "Media Cost Indices" were the only comprehensive set of measures available for tracking year-to-year changes in the costs of reaching audiences (CPMs or cost per millions of readers/listeners/viewers) in different media. Annually, McCann/Interpublic reported cost indices for a set of media along with two "composite" indices; one "included all National and Local budgets" (CNTCPM) and the other, "National budgets only" (CNLCPM). ${ }^{32}$ Those indices were apparently discontinued in 2007, at the same time McCann Erickson introduced the Magna Global measures of aggregate advertising spending based on the advertising receipts of media suppliers. ${ }^{33}$

In Figure 6 we plot the pair of MCE Composite Price Indices (CNLCPM and CNTCPM) along with the BLS' Producer Price Index for Finished Goods (PPIFGA) and the Bureau of Economic Analysis' (BEA's) GDP Implicit Price Deflator (RGDPIPD), all for the 47-year period 1960-2006. ${ }^{34}$ As may be seen from Figure 6, up through the early 1980s, the four series tracked (Insert Figure 6 Somewhere Near Here)

\footnotetext{
${ }^{31}$ Blank [1963], p. 33.

${ }^{32}$ For example, an unpublished report of "Universal McCann Media Cost Indices", dated August 2005, presented separate price indexes $(1982-84=100)$ for a set of eight media plus the two composite indices for the period 1960-2005.

${ }^{33}$ Mandese [2009b]. Implicit aggregate price indices for a variety of advertising media mixes using Laspeyres or Paasche aggregation methods have been reported at various times in the advertising literature, but have turned out to be "one-off" ad hoc projects that were not sustained. See Bachman [1967], Schmalensee [1972], Ehrlich and Fisher [1972], Fisher and Ehrlich [1984], and Silk, Klein and Berndt [2002].

${ }^{34}$ CNTCPM data is not available for 2007, but 2007 values for CNLCPM are 265.3, for PPIFGA 162.220, and for RGDPIPDA 181.243.
} 
each other quite closely. However, from the early 1980s onward, each of the MCE Composite Advertising Indices grew at rates exceeding the increases of both the PPI for Finished Goods and the GDP Implicit price deflator, implying that with these composite media price indices, the real price of advertising was increasing over that time period by almost $70 \%$. Specifically, indexed to $1982-1984=100$, the 2006 CNLCPM and CNTCPM index values of 261.8 and 299.9, respectively, exceeded the 2006 PPIFGA and RGDPIPDA values of 156.183 and 176.501, respectively.

Moreover, these data document that since the early 1980s onward, the MCE's National Budgets Only CNTCPM grew by about $11 \%$ more than did the combined MCE National and Local Budgets CPM CNLCPM, implying that national advertising prices were growing more rapidly than local advertising prices. Notably, this was the era when advertisers' concerns about 'media price inflation" were aroused, particularly for national television. ${ }^{35}$

Turning to advertising media price data availability from public sector sources, we note the U.S. Bureau of Labor Statistics (BLS) has collected unit volume and value of shipments data from establishments going back to 1902, and initially used these data to construct its Wholesale Price Index (WPI) as an unweighted average of price relatives for about 250 commodities. In 1978, the WPI was replaced by the Producer Price Index (PPI) program. The PPI measures the average change over time in the selling prices received by domestic producers for their output. The prices included in the PPI are from the first commercial transaction for many products and some services. ${ }^{36}$

Although initially WPI prices were measured for specific commodities, to be consistent with other economic data BLS gathered from establishments, all sampled establishments were classified by industry, where the industry within which an establishment was classified was determined by those products that accounted for the largest share of the establishment's total value of shipments - called the establishment's primary product. Most industries also have secondary product indices that show changes in prices received by establishments in the

\footnotetext{
${ }^{35}$ See Arzaghi et al. [2012], pp. 5-6, and the references cited therein for further discussion. Appendix Table 1 presents summary statistics for the four price indices displayed in Figure 3. Note that these four price indices are exceedingly highly intercorrelated, with the Pearson correlation coefficients varying from 0.938 to 0.996 . The CNTCPM series is, however, relatively more variable than CNLCPM; the respective coefficients of variation are 0.7241 and 0.6676 .

${ }^{36}$ BLS Handbook of Methods [not dated], "Producer Prices", ch. 14, pp. 1-5.
} 
industry for products made chiefly in some other industry. The BLS PPI program has collected data on both primary and secondary products at each establishment. ${ }^{37}$

As an alternative to an industry-based classification, the BLS has for many years constructed and published a commodity classification of its PPI that organizes products "by similarity of end use or similarity of material composition regardless of whether the products are classified as primary or secondary in their industry of origin." ${ }^{38}$ Although the industry-based PPI has been published for various service industries since 1979, prior to January 2009 the commodity classification system included only goods-based price indices and excluded services, thereby excluding services that were classified as commodities. With the release of data for January 2009, PPI expanded the commodity classification structure to include services and construction products. ${ }^{39}$ As a result, unlike some other media prices, newspaper and periodical commodity PPI price indexes may contain data going back before 2009 , because newspapers and periodicals (and several other media such as series for directories and mailing lists) may have previously been classified as manufacturing industries rather than services.

In 2009 the BLS introduced all of its Services commodity indexes (designated with the prefix WPU). Figure 7 depicts a portion of the hierarchical structure of the current set of Advertising Media Price Indices published by the BLS; the Figure is incomplete in that it omits

(Insert Figure 7 Somewhere Near Here)

several tiers below the second tier. The structure consists of at least three tiers or levels. The top tier here is WPU 36, "Advertising Time and Space Sales", which is a 2012 fixed weight Laspeyres aggregation across four three-digit sub-aggregates for advertising space sales in periodicals, newspapers, directories and mailing lists (WPU 361), television (WPU 362), radio (WPU 363) and internet advertising sales, the latter excluding internet advertising sold by print publishers (WPU 365). The next tier has several four-digit sub-aggregates, such as WPU 3611 advertising space sales in periodicals and newspapers and WPU 3612 - advertising space sales in directories and mailing lists. Several six-digit subaggregates are omitted, but under them are three eight-digit tiers - specialized business and professional periodicals (WPU 3611-0101), general and consumer periodicals (WPU 3611-0102) and newspapers, print only (WPU 3611-

\footnotetext{
${ }^{37}$ BLS Handbook of Methods [not dated], op. cit., pp. 4-5.

${ }^{38}$ Id.

${ }^{39} \mathrm{ld}$.
} 
0203). By comparison, the three-digit television subaggregate WPU 362 has three six-digit subaggregates - Broadcast and Network (WPU 362101), Cable Network (WPU 362102) and Local Cable Systems (WPU 362103), currently the three digit WPU 363 for radio has no more detailed sub-tiers. It appears the eight-digit level of detail is the most detailed level at which the BLS PPI program publishes prices. The number of tiers may change over time as industries evolve and the BLS is able to obtain voluntary price quotes from the sampled establishments. ${ }^{40}$

Three issues are particularly relevant here. As noted above, WPU 365 excludes internet advertising sold by print publishers. BLS officials have informed us that firms that publish both in print and online formats fall into the "traditional" media format (periodical or newspaper) in which they primarily publish (WPU 3611 and a lower tier). For this reason the BLS' digital advertising data are currently dispersed or distributed among different PPI indices, rather than being combined into a single "digital" three-digit subaggregate. While the PPI currently does not publish a single index that captures all US digital advertising prices, discussions are currently underway regarding how the PPI program could adapt to the changing North American Industry Classification System (NAICS) structure, and how it could consolidate all of the digital advertising price data into one index. One alternative hierarchical possibility is that of the Magna Global structure displayed in Figures 2a and 2b. Note that while Magna Global collects price data for outdoor/out-of-homed $(\mathrm{OOH})$ advertising as a separate stratum, currently the BLS structure depicted in Figure 7 contains no distinct outdoor/OOH advertising stratum.

Second, the existence of several tiers or stages of aggregation across the various media price indices raises the practical question of whether the alternative possibilities of creating subcategories and aggregating them affects the top level price index WPU 36 Advertising Time and Space Sales. For example, if the various digital price media were aggregated into a single composite Digital price index, rather than being distributed across WPU 365 and several "traditional" media formats such as in WPU 3611, WPU 362 and WPU 363, how would the "master" or "top tier" WPU 36 price index measure have been affected?

\footnotetext{
${ }^{40}$ A comparable BLS hierarchical figure to Figure 7 could be drawn for the Advertising and Related Services industry, which is a component of WPU45 Professional Services, and nested underneath that is WPU455 Advertising and Related Services, and WPU4551 Advertising Agency Services. See, for example, U.S. Bureau of Labor Statistics, PPI Detailed Report [2020], Table 9, p. 80.
} 
According to the economic theory of index numbers, when a top tier price index is numerically invariant to the hierarchical placement and ordering of sub-indexes and lower tier elementary price indexes, it is said to be consistent in aggregation - an obviously desirable characteristic of an index number procedure, else aggregate measures of inflation of a universe of products and services would depend on the somewhat subjective and discretionary hierarchical and nesting structure of products and services. Fortunately, as has been shown by, among others, W. Erwin Diewert, the fixed weight Laspeyres, fixed weight Paasche, chained weight Laspeyres, and chained weight Paasche index procedures each possesses the property of consistency in aggregation when the hierarchy consists of two stages, as do some but not all other well-known index number procedures. ${ }^{41}$

Third and perhaps most importantly for facilitating research on the U.S. advertising industry, recall that the BLS launched the Advertising Time and Space Sales industry classification in 2009. Although prior to 2009 it collected data on newspaper and periodical advertising (when considering them part of manufacturing), for most of the media advertising tiers in Figure 7, BLS media-specific price data are non-existent for years prior to 2009 or 2010. An implication is that for a medium such as Digital that mushroomed from nothing in 1995 to a 15 percent market share in 2010 and 48 percent share in 2018 (see Figure 4), there is no historical price series available from BLS that captures and embodies this striking development. Absent these media-specific data, any aggregate BLS advertising price index from 2010 onward also necessarily fails to incorporate the pre-2010 compositional changes. While underlying price and volume data of the various media services may be available in the archives of scattered private sector or public sector libraries, they remain to be discovered, curated and made publicly available.

It is clear that most all detailed econometric analyses of time series of advertising spending levels require price indices for purposes of adjusting expenditure data for changes in advertising media composition, volume and prices, thereby facilitating comparisons of nominal (current prices) and real (constant quality) indices.

\footnotetext{
${ }^{41}$ See, for example, W. Erwin Diewert ([1978],[2015]). In personal correspondence, Prof. Diewert has shown that these two-stage consistency in aggregation properties also hold with Laspeyres and Paasche indices when the number of stages is three rather than two. He has also conjectured that the proof of consistency in aggregation can be generalized to $\mathrm{N}$ stages for all $\mathrm{N} \geq 2$.
} 
Note that the compilation and publication of media-specific and aggregate advertising price indexes encompassing the pre- and post-digital advertising epochs would contribute substantively to the understanding of issues concerning not only historical issues involving the real or nominal elasticity of advertising expenditures with respect to GDP, but also affects current public policy issues regarding the impact of eliminating the tax deductibility of corporate advertising expenses, the reliability and credibility of calculated rates of return on investments in digital vs. non-digital media advertising, the procyclicality of media advertising, and the effects of eliminating direct-to-consumer advertising of pharmaceuticals and other medical products and services.

Absent such data, it is still worthwhile to investigate whether, using the existing admittedly incomplete and blemished available data, there is evidence suggesting major structural changes in the aggregate advertising - GDP relationship have occurred contemporaneous with the introduction of digital and internet advertising.

\section{ANALYTICAL FRAMEWORK}

We denote real gross domestic product at time period t as $\mathrm{RGDP}_{\mathrm{t}}$, nominal gross domestic product at time t as $\mathrm{NGDP}_{\mathrm{t}}$, and the gross domestic product implicit price deflator that links real and nominal gross domestic product at time $t$ as GDPIPD $_{t}$. By definition,

(Eq. 1) $\mathrm{NGDP}_{\mathrm{t}} \equiv \mathrm{RGDP}_{\mathrm{t}}{ }^{*} \mathrm{GDPIPD}_{\mathrm{t}}$, or in logarithms, $\log \left(\mathrm{NGDP}_{\mathrm{t}}\right)=\log \left(\mathrm{RGDP}_{\mathrm{t}}\right)+\log \left(\mathrm{GDPIPD}_{\mathrm{t}}\right)$.

Denoting nominal expenditures on advertising at time $t$ as $N A D V_{t}$, we specify a relatively straightforward double logarithmic relationship between nominal advertising expenditures at time $t$ and nominal GDP at time $t$ as

(Eq. 2) $\log \left(N A D V_{t}\right)=\alpha+\beta * \log \left(N G D P_{t}\right)$.

If one allows for the possibility that the real GDP and implicit price deflator components of nominal GDP can have differential impacts on nominal advertising expenditures, we can generalize (Eq. 2) to

(Eq. 3) $\log \left(\mathrm{NADV}_{\mathrm{t}}\right)=\alpha+\beta_{1} * \log \left(\mathrm{RGDP}_{\mathrm{t}}\right)+\beta_{2} * \log \left(\mathrm{GDPIPD}_{\mathrm{t}}\right)$

where $\beta_{1}$ is the elasticity of nominal advertising with respect to real GDP, and $\beta_{2}$ is the elasticity of nominal advertising with respect to the GDP implicit price deflator. An interesting special 
case of (Eq. 3) arises if one hypothesizes that the two elasticities $\beta_{1}$ and $\beta_{2}$ are equal, with, say, their common value being $\beta$, i.e.,

(Eq. 4) $\beta_{1}=\beta_{2}=\beta$.

In this case we can simplify (Eq. 3) to

(Eq. 5) $\log \left(N A D V_{t}\right)=\alpha+\beta^{*}\left[\log \left(R G D P_{t}\right)+\log \left(G D P I P D_{t}\right)\right]=\alpha+\beta^{*} \log \left(N G D P_{t}\right)$

which transforms the multivariate relationship between advertising and GDP in (Eq. 3) into a simpler bivariate nominal advertising expenditures on nominal GDP econometric model specification, where $\beta$ is the elasticity of nominal advertising with respect to nominal GDP. If one hypothesizes that this $\beta$ elasticity equals 1.0, we can transform (Eq. 5) into the even simpler relationship

(Eq.6) $\log \left[\mathrm{NADV}_{\mathrm{t}} / \mathrm{NGDP}_{\mathrm{t}}\right]=\alpha$,

in which case the nominal advertising expenditure to GDP ratio is a constant equal to $\alpha$. Note that the parameter restrictions $\beta_{1}=\beta_{2}=\beta$ and then $\beta=1$ are separate testable restrictions that can be evaluated empirically, and that it is also possible to test the hypotheses jointly, i.e., test whether

(Eq. 7) $\beta_{1}=\beta_{2}=1$.

An alternative analytical framework involves first differences in log(ADV), log (NGDP), log (RGDP) and log (GDPIPD) rather than their levels. In this case Eqn. (1) above is unchanged, but Eqn. (2) becomes

(Eq. 2') $\log \left(\mathrm{NADV}_{\mathrm{t}} / \mathrm{NADV}_{\mathrm{t}-1}\right)=\delta+\beta^{*} \log \left(\mathrm{NGDP}_{\mathrm{t}} / \mathrm{NGDP}_{\mathrm{t}-1}\right)$

where the constant term $\alpha$ drops out of (Eq. 2) and is replaced by a constant growth rate $\delta$, i.e.,

(Eq. 3') $\log \left(\mathrm{NADV}_{\mathrm{t}} / \mathrm{NADV}_{\mathrm{t}-1}\right)=\delta+\beta_{1}{ }^{*} \log \left(\mathrm{RGDP}_{\mathrm{t}} / \mathrm{RGDP}_{\mathrm{t}-1}\right)+\beta_{2}{ }^{*} \log \left(\mathrm{GDPIPD}_{\mathrm{t}} / \mathrm{GDPIPD}_{\mathrm{t}-1}\right)$

but where the interpretations of $\beta_{1}$ and $\beta_{2}$ remain unchanged as elasticities of nominal advertising expenditures with respect to real gross domestic product and with respect to the gross domestic product implicit price deflator, respectively. When the $\beta_{1}=\beta_{2}=\beta$ restrictions in Eq. (4) are imposed, one obtains a revision of Eqn. (5) involving growth rates rather than levels, i.e., 


$$
\text { (Eq. 5') } \begin{aligned}
\log \left(\mathrm{NADV}_{\mathrm{t}} / \mathrm{NADV}_{\mathrm{t}-1}\right) & =\delta+\beta^{*}\left[\log \left(\mathrm{RGDP}_{\mathrm{t}} / \mathrm{RGDP}_{\mathrm{t}-1}\right)+\log \left(\mathrm{GDPIPD}_{\mathrm{t}} / \mathrm{GDPIPD}_{\mathrm{t}-1}\right)\right] \\
& =\delta+\beta^{*}\left[\log \left(\mathrm{NGDP}_{\mathrm{t}} / \mathrm{NGDP}_{\mathrm{t}-1}\right)\right]
\end{aligned}
$$

where $\beta$ is the (constant) elasticity of nominal advertising expenditures with respect to nominal gross domestic product. If one further constrains this constant elasticity to be unity, we obtain a variation of Eqn. (6) in which the growth rate of the NADV/NGDP ratio is equal to a constant $\delta$, i.e.,

(Eq. $\left.6^{\prime}\right) \log \left[\left(\mathrm{NADV}_{\mathrm{t}} / \mathrm{NGDP}_{\mathrm{t}}\right) /\left(\mathrm{NADV}_{\mathrm{t}-1} / \mathrm{NGDP}_{\mathrm{t}-1}\right)\right]=\delta$

As before, the parameter restrictions $\beta_{1}=\beta_{2}=\beta$ and then $\beta=1$ are separate and sequential testable restrictions that can be evaluated empirically, but it is also possible to test these hypotheses jointly, i.e., test whether simultaneously $\beta_{1}=\beta_{2}=1$. Moreover, one can test whether the advertising to GDP ratio is constant by comparing goodness of fit in Eqns. (3), (5) and (6).Alternatively, one can discern whether a structural break has occurred over time by determining whether the growth rate of the advertising-GDP ratio is constant, by comparing goodness of fit in Eqns. $\left(3^{\prime}\right),\left(5^{\prime}\right)$ and $\left(6^{\prime}\right)$.

\section{ECONOMETRIC METHODS}

Denote the natural logarithms of MCE\$BN, IRS\$BN, and MG8\$BN as LGMCE\$BN, LGIRS\$BN and LGMG8\$BN, respectively. To determine the properties of our logarithmic nominal advertising expenditure time series process for LGMCE\$BN and LGIRS\$BN, we calculate their autocorrelation and partial autocorrelation coefficients using the EViews Version 9 econometric software program, ${ }^{42}$ and annual data covering the 1960-2007 time period. We summarize the time series properties in correlograms. In addition to examining raw (levels) data, we first, second, third and further difference the data as necessary until the autocorrelation functions exhibit stationarity. Conditional on achieving stationarity, when initiating regression equation estimation, we also utilize the autocorrelation and partial autocorrelation coefficients of the estimated time series processes to provide preliminary guidance in the choice of the order of possible moving average or autoregressive function specifications. ${ }^{43}$

\footnotetext{
${ }^{42}$ EViews 7 User Guide II (Quantitative Micro Software, Irvine, CA [1994-2007]), www.eviews.com. . ${ }^{43}$ We employ time series methods as described in Part 4 (chapters 15-19) of Pindyck and Rubinfeld [1998].
} 
For the regression equation estimation, we estimate both log-level (raw) and firstdifferenced logarithmic linear models by OLS, and then allow and test for the presence of AR1 and AR2 autocorrelation as well as first and second order moving average disturbances. ${ }^{44}$

\section{EMPIRICAL RESULTS}

\section{VI.1 Stochastic Time Series Analysis Findings}

In Figure 8 we reproduce correlograms for the log-level raw aggregate nominal McCannErickson advertising expenditures (LGMCE\$BN) - left top panel - and raw aggregate nominal Internal Revenue Service (LGIRS\$BN) - right top panel; in the bottom panel, we reproduce correlograms for the first-differenced log aggregate nominal McCann-Erickson advertising expenditures (MCENG) - left panel - and for the first-differenced log aggregate nominal Internal

(Insert Figure 8 Somewhere Near Here)

Revenue Service advertising expenditures (IRSNG) - right panel. The dotted vertical lines in each of the correlograms are the approximate two standard error bounds; if an autocorrelation (AC) or partial autocorrelation (PAC) coefficient is within these bounds, it is not significantly different from zero at (approximately) the $5 \%$ significance level. The rows of the correlogram indicate the $A C$ and PAC coefficients for the series $k$ years apart - here, up to 20 years apart. The last two columns are the Bartlett Q-statistics and their p-values. The Q-statistic at lag $\mathrm{k}$ is a test statistic for the null hypothesis that there is no autocorrelation up to order k.

Denoting the autocorrelation of a time series at lag $\mathrm{k}$ as $\mathrm{r}_{\mathrm{k}}$ (the correlation coefficient of the time series $k$ years apart), in the top panel of Figure 8 we observe that log-levels of the MCE and IRS advertising expenditure series are very similar, each revealing an initially very significant but monotonically and geometrically declining $\mathrm{AC}$ coefficient, and becoming statistically insignificant after about a 12 to 13 year lag. The large Q-statistic indicates joint statistical significance of the $r_{k}$ coefficients (more precisely, rejection of the null hypothesis that the $r_{k}=0$ up through $k=20$ ). This pattern of estimated AC coefficients is consistent with the LGMCE\$BN and LGIRS\$BN being stationary time series, and obeying a lower order autoregressive process. In addition, that the estimated AC coefficients are statistically significant even after a substantial number of lags suggests the time series data are not being generated by a low-order moving average process.

\footnotetext{
${ }^{44}$ See Charles M. Beach and James G. MacKinnon [1978] for discussion of computational considerations.
} 
Notice that the PAC coefficient at lag 2 is insignificant (it is within the two standard error vertical bounds) is consistent with the time series being generated by an $A R(1)$ process.

The bottom panels of Figure 8 are correlograms for the log first-differenced data (i.e., growth rates). For MCENG, the estimated AC coefficients do not decline monotonically, they become statistically insignificant at the three-year lag, and become negative after six years. Moreover, since all the PAC coefficients fall within the two standard error vertical bounds beginning with lag 2 , they suggest at most an $A R(1)$ data generating process. The estimated $A C$ coefficients for the IRSNG first differenced series are positive up through a lag of 12 years, but become statistically insignificant after four years.

In summary, the correlograms of the LGMCE\$BN and LGIRS\$BN are very similar, each suggesting stationarity, the possibility of having been generated by an $A R(1)$ process, and unlikely to have been generated by a moving average process. The log-first differenced MCENG and IRSNG series yield similar qualitative inferences, although they are not quite as similar as those based on the log raw (level) data. In terms of providing preliminary guidance for regression estimation, bearing in mind that residuals from estimated regression equations may not mimic the time series properties of the dependent variable, we nonetheless find support for analyzing by regression methods both log raw (levels) and first-differenced log advertising expenditure models, and because of the stationarity we seem to have observed, we have some support for estimating regression models using ordinary least squares (OLS), $A R(1)$ and perhaps $A R(2)$ models.

However, given the relatively large value of the estimated AC coefficients at short lags displayed in the correlograms of Figure 8, we believe it prudent to perform unit root tests for LGMCE\$BN and LGIRS\$BN in levels, first-and second-differences. Recall that if the data series contains one or more unit roots, then standard inference procedures such as those implicit in the correlograms of Figure 8 do not apply. The augmented Dickey-Fuller unit root tests the null hypothesis of a unit root against a one-sided alternative hypothesis of a stationary series, and is implemented in the EViews software program using one-sided critical p-values for these tests as developed by James $\mathrm{G}$. MacKinnon. ${ }^{45}$

\footnotetext{
45 James G. MacKinnon [1996].
} 
In log-levels, for both LGMCE\$BN and LGIRS\$BN we cannot reject the null hypothesis of unit roots; the test-statistics are -0.2282 and -0.22192 , respectively, with p-values of 0.9905 and 0.9906. For first-differences, however, the null hypothesis that first differences of LGMCE\$BN and LGIRS\$BN have unit roots is rejected; the test statistics are -4.6112 and -4.1419 , with $p$ values of 0.0030 and 0.0108 , respectively. Rejections of the unit root null hypothesis are even more decisive with second-differences in LGMCE\$BN and LGIRS\$BN; the augmented DickeyFuller test statistics are -9.910 ( $p$-value of $<0.0001$ ) and -6.9903 ( $p$-value of $<0.0001$ ), respectively. These unit root test results therefore lend support for implementing regression analyses using the first-differenced data, but call into question the reliability of findings from the log-level models. Below, for comparison purposes we report regression results using alternatively log-level and log-first-differenced data series for LGMCE\$BN and LGIRS\$BN.

\section{VI.2 Initial Regression Analysis Findings: Annual MCE and IRS Data, 1960-2007}

We estimate parameters in the logarithmic raw (level) data of (Eq. 3) -the "most general" model and (Eq. 5) - the "restricted model" -- by ordinary least squares (OLS), and by maximum likelihood (ML) allowing for first order autoregressive (AR1), and both first and second order autoregressive (AR2) disturbances. ${ }^{46}$ Natural logarithms of nNominal advertising expenditures as measured by McCann-Erickson (LGMCE\$BN) or the Internal Revenue Service (LGIRS\$BN) are the alternative dependent variables encompassing the 1960-2007 time frame. Results from these regression equations are presented in Table 1 . We then also estimate parameters in the first-differenced "most general" (Eq. 3') model and the "restricted" (Eq. 5') specification by OLS, and AR1 and AR2 maximum likelihood methods, first with $D(L G M C E \$ B N)$ and then with $D(L G I R S \$ B N)$ as the first-differenced logarithmic (growth rate) dependent variable over the 1961-2007 time period. Results from these regressions are presented in Table 2.

We highlight six sets of findings in Table 1. First, over the same 1960-2007 time period, for each of the three estimation methods, results based on the MCE data are very similar to those based on the IRS data; this is seen by comparing results across the left and right panels in columns for OLS estimates, for AR1 estimates and for AR2 estimates. Second, some results are

\footnotetext{
${ }^{46}$ Although we estimated combined autoregressive and moving average model specifications, none of the first and second order moving average coefficients were statistically significant, and thus we do not report them here.
} 
(Insert Table 1 Somewhere Near Here)

quite sensitive to the estimation method. For example, point estimates and $\rho$-values for AR1 or AR2 disturbances can differ substantially from those based on OLS estimates. In the top panel of Table 1, with OLS estimation the Durbin-Watson test statistics are very low - 0.201 (MCE data) and 0.227 (IRS data). If autocorrelation is indeed present, then standard errors based on OLS estimates are likely to be downward biased. In both panels of Table 1, when one compares standard error estimates based on AR1 or AR2 estimation with those based on OLS, we observe that the latter are $50 \%$ to $100 \%$ or more greater than the OLS estimated standard errors, likely due to the fact that estimates of $\rho_{1}$ are greater than 0.93 and are significantly different from zero in both the AR1 and AR2 columns. Third, the presence of autocorrelation affects inference on whether the $\beta_{1}=\beta_{2}=\beta$ null hypothesis is supported empirically; as seen in the row just above the top of the bottom panel in Table 1, this equal elasticity hypothesis is rejected at just under the $0.10 \mathrm{p}$-value with MCE data and much more decisively at the $<0.01$ level with the IRS data when OLS is the estimation method, but is not rejected at conventional confidence levels when AR1 or AR2 estimation methods are employed.

Fourth, when one imposes the $\beta_{1}=\beta_{2}=\beta$ null hypothesis, as seen in the bottom panel of Table 1, estimates of the $\beta$ elasticity are all close to 1.0; but because these estimates are plagued by the presence of autocorrelation, under OLS estimation the nested hypothesis test that $\beta=1$ is decisively rejected (MCE $p$-value of 0.0008 and IRS $p$-value of $<0.0001$ ), whereas with AR1 or AR2 estimation this hypothesis is not rejected. Fifth, although estimates of $\rho_{1}$ in the top and bottom panels of Table 1 are always greater than 0.92 and are statistically significantly different from zero at the $0.01 \mathrm{p}$-value level, only one of the four estimates of $\rho_{2}$ reaches statistical significance, and that is only at a p-value of 0.10 . Notably, however, the point estimates of $\rho_{2}$ are all negative. Hence, with this level (raw) logarithmic data, it appears that AR2 estimation is unnecessary, and that AR1 estimation adequately accounts for the autocorrelated disturbance process. Sixth, recall, however, that all these log-level results in Table 1 must be viewed with considerable skepticism since the unit root test results reported earlier suggest that the log-levels data is generated by a unit root process, while for both the first- and second-differenced data the unit root hypothesis was rejected. An implication is that conventional statistical inference of results reported in Table 1 may not be valid. Thus we now 
move on to discuss regression findings based on the fi-differenced data, reported in Table 2 , and compare them with those based on the level (raw) logarithmic data in Table 1.

Comparing the top panels of Tables 1 and 2 in which the respective parameter estimates in the level-logarithms and first-differenced logarithms Eqs. 3 and $3^{\prime}$ are reported, we observe first that while estimates of the $\beta_{1}$ and $\beta_{2}$ elasticities are centered around unity in the level-

(Insert Table 2 Somewhere Near Here)

logarithms in Table 1, these elasticity estimates are generally greater in the first-differenced logarithmic models of Table 2 where they are centered around 1.4 or 1.5. Moreover, they are quite similar in magnitude across the OLS, AR1 and AR2 specifications, and in almost all cases are significant at the 0.01 level. In all but the OLS cases in Table 1, point estimates of the real GDP elasticity $\beta_{1}$ are greater than estimates of the implicit price deflator elasticity $\beta_{2}$. However, a notable difference between estimates in the two tables is that while the OLS estimates in the level-logarithms of Table 1 exhibit statistically significant AR1 autocorrelation, in the firstdifferenced logarithmic models in Table 2, none of the OLS, AR1 or AR2 models displays statistically significant autocorrelation. Furthermore, although the null hypothesis that the $\beta_{1}$ and $\beta_{2}$ elasticities are equal is rejected in the OLS estimates of Table 1 but is not rejected for each of the AR1 and AR2 models of Table 1, in Table 2 with the first-differenced logarithmic data this null hypothesis of elasticity equality is never rejected. As seen in the bottom panel of Table 2 , at about 1.4, estimates of $\beta$-- the elasticity of nominal advertising with respect to nominal GDP - are larger with the first-differenced data (and significantly different from unity) than the $\beta$ estimates of around 1.0 in Table 1 based on levels (raw) logarithmic data. However, it is notable that while their numerical values differ modestly, in general the elasticity estimates are qualitatively similar across the MCE and IRS data sets, both in the level- (Table 1) and firstdifferenced logarithmic (Table 2) data. Finally, when one simultaneously imposes the restrictions $\beta_{1}=\beta_{2}=1$ (even though these are rejected with the first-differenced logarithmic data) and estimates the single parameter $\delta$ as in Eq. $6^{\prime}$, one obtains an estimate of the annual growth rate of the nominal advertising expenditure to nominal GDP ratio; while this annual growth rate estimate ranges between -0.0028 (OLS), -0.0034 (AR1) and -0.0041 (AR2), with the MCE data (results not shown in Table 2), with the IRS data the estimates are positive, ranging between 0.0018 (AR2), 0.0019 (AR1) and 0.0024 (OLS). As seen in the bottom row of Table 2, 
the null hypothesis that the annual growth rate of this nominal advertising to nominal GDP ratio is zero is not rejected - the $p$-values are each greater than 0.54 .

\section{VI.3 Additional Time Series and Regression Analysis Findings: Annual MG8 Data, 1980-2018}

As discussed earlier, the annual MCE nominal advertising expenditure data are available for the 1960-2007 time period, while publicly available annual IRS data are currently available up through 2014. To explore potential differences in the MCE and IRS data, in the previous paragraphs we have provided stochastic time series and regression analysis findings covering the 1960-2007 years overlapping both data sources.

Although compilation and publication of the MCE data by the McCann-Erickson subsidiary of Interpublic terminated in 2007, Magna Global, the strategic global media unit of Interpublic Group, utilizes data on advertising revenues obtained from media owners in the U.S. Magna Global (hereafter, MG) introduced a new measurement methodology in 2009 that focuses on advertising revenues reported by the various media industry sectors rather than costs and expenses incurred by advertisers. The total Magna Global Expenditure series ("MG8") includes national and local data on eight media: television, digital, newspapers, magazines, radio, out of home, directories and direct mail. ${ }^{47}$ To facilitate transition from Interpublic's McCann-Erickson unit, Magna Global has readjusted Interpublic's MCE historical annual advertising estimates going back to 1980 based on the new measurement methodology. MG8 total nominal expenditure data for the US is currently available encompassing the 1980-2018 time frame. We now compare MCE and IRS 1960-2007 advertising elasticity estimates with MG8 estimates based on the shorter 1980-2007 time period, and then extend the MG8 time frame to include also the 2008-2018 years, giving us a 39 year MG8 series for 1980-2018 that also enables us to exp lore whether the advertising-GDP relationship is stable or is changing in recent years.

As is evident from Figure 3 and discussed in the section 3.2.3, the total media revenue series MG8 for advertising is less than that for MCE and IRS advertising expenditure series since the latter include not only media advertising costs, but also costs of advertising creative and production services, which for many years were bundled with media placement services.

\footnotetext{
${ }^{47}$ See Magna Global [2015].
} 
Before we implement regression analysis, we first examine whether the MG8 series is stationary, or is generated by a unit root process that is non-stationary, in levels and/or in differenced form, in raw or logarithmic units over the 1980-2018 time period. Analysis based on the augmented Dickey-Fuller test reveals that we cannot reject the null hypothesis of a unit root based on the raw level MG8 data ( $p$-value of 0.5457 ) and we cannot reject the null hypothesis of a unit root based on the logarithmic raw level data ( $p$-value of 0.5307$)$, but we can reject the null hypothesis of a unit root based on the first-differenced logarithmic data at usual significance levels ( $p$-value of 0.0138 ). Since the validity of conventional regression inference requires that the underlying series be the result of a stationary data generating process, we now proceed with regression analysis where the dependent variable is the first-differenced logarithmic MG8 revenue series, hereafter denoted as $D(L O G M G 8 \$ B N)$. In Table 3, we report regression estimates of parameters in the most general Eq. $3^{\prime}$ and the restricted Eq. $5^{\prime}$ with $\mathrm{D}($ LOGMG8\$BN) as the dependent variable. To facilitate comparison with earlier findings and to (Insert Table 3 Somewhere Near Here)

examine parameter stability over time, we report OLS, AR1 and AR2 findings over the truncated 1981-2007 time period (with 2007 being the final year, as was the case with the MCE and IRS findings reported in Tables 1 and 2), and then over the extended 1981-2018 time frame that includes more recent years. We also test for parameter stability over the 1981-1999 and 20002018 sub-periods (with 2000 being the breakpoint year) by performing Chow tests using the likelihood ratio test statistic. ${ }^{48}$

There are several striking findings in Table 3, all pointing to inclusion of the most recent data leading to larger estimates of advertising elasticities. First, if one compares estimates of $\beta_{1}$ and $\beta_{2}$ with the MG8 advertising expenditure data over the 1981-2007 time period (the left panel of Table 3) with the MG8 advertising expenditure data over the 1981-2018 years (the right panel of Table 3), we observe that the elasticity estimates become larger when more recent years are included in the data set; estimates of $\beta_{1}$, for example, average about 1.7 with 19812007 MG8 data, but increase to about 2.4 when 1981-2018 MG8 data are utilized; for $\beta_{2}$, the

\footnotetext{
${ }^{48}$ For discussion of the likelihood ratio and other statistics to test the null hypothesis of parameter stability in the context of AR1 and AR2 processes estimated by maximum likelihood, see the EViews 7 User Guide II, Version 9 (Quantitative Micro Software, Irvine, CA [1994-2009], www.eviews.com), ch. 14, "Specification and Stability Tests".
} 
respective average estimates are about 0.9 and 1.3. The null hypothesis that the elasticities $\beta_{1}=$ $\beta_{2}$ is not rejected based on 1981-2007 MG8 data, but is decisively rejected when elasticity estimates are based on the 1981-2018 MG8 data. It is also notable that these MG8- based elasticity estimates in Table 3 are greater than the 1981-2007 elasticity estimates based on MCE and IRS data. When the $\beta_{1}=\beta_{2}=\beta$ constraint is imposed on the 1981-2007 data (Eq. 5' estimates in the bottom panels of Tables 2 and 3 ), the additional restriction that $\beta=1$ is rejected with the MCE data and with the IRS data, but with the MG8 data it is not rejected at p-values < 0.05 . However, as seen in the bottom right panel of Table 3 , this $\beta=1$ hypothesis is decisively rejected (all p-values $<0.001$ ) when the elasticity estimates are based on data including all the 1981-2018 annual values.

A second notable finding emerges when one compares autoregressive parameter estimates across all three tables. When based on 1980-2007 MCE and IRS logarithmic in levels data, in all models in Table 1 the estimates of the first-order autocorrelation coefficient $\rho_{1}$ are significantly different from zero, and all but one of the estimates of the second-order autocorrelation coefficient $\rho_{2}$ are insignificantly different from zero, and that single instance is only significant at a p-value of 0.10. Recall, however, that based on the Augmented DickeyFuller test, the null hypothesis that the log (raw) levels MCE and IRS were generated by a unit root process could not be rejected, implying that the validity of conventional statistical inference procedures was called into question with this log (raw) levels data. When the 19812007 log MCE and log IRS data are first differenced however, as seen in Table 2, none of the $\rho_{1}$ and $\rho_{2}$ estimates is statistically significant; recall that with this 1981-2007 first-differenced log MCE and log IRS data, the unit root hypothesis was rejected, implying that stationary conditions necessary for valid statistical inference in Table 2 were satisfied with the 1981-2007 firstdifferenced log MCE and log IRS data. Finally, when the first-differenced 1981-2018 log MG8 data were analyzed, the unit root hypothesis was rejected, rationalizing use of this data for regression estimation of the advertising elasticities. As seen in Table 3, when the firstdifferenced 1981-2018 log MG8 data are employed, none of the estimated $\rho_{1}$ and $\rho_{2}$ autoregressive parameters was statistically significant. We conclude, therefore, that use of firstdifferenced log MCE, log IRS, and log MG8 data are not compromised by the presence of a unit root data generating process, although use of level (raw) log MCE and IRS data appear to suffer from the unit root phenomenon.

Third, and perhaps most importantly, the finding in Table 3 that estimates of the real 
GDP $\beta_{1}$ and implicit GDP price deflator $\beta 2$ elasticities increase when one adds more recent years to the 1981-2007 data set and includes annual values through 2018, raises the issue of whether these elasticity estimates are stable or instead differ over time. We have implemented the Chow test of parameter equality, choosing 2000 as the breakpoint year, and tested whether parameter estimates in Eq. $3^{\prime}$ and in Eq. 5' are stable across the $1981-1999$ (20 ${ }^{\text {th }}$ century) and 2000-2018 ( $21^{\text {st }}$ century) time periods. Results are displayed in the rows designated "Chow 2000 break" for Eq. 3' (middle of Table 3) and for Eq. 5' (bottom of Table 3). What we find is that the null hypothesis of parameter equality over selected years in the $20^{\text {th }}$ and $21^{\text {st }}$ century is decisively rejected, with all p-values being $<0.001$ for Eq. $3^{\prime}$ and $<0.03$ for Eq. $5^{\prime}$.

Together, these findings raise the issue, what happened during years near the turn of the century that resulted in nominal MG8 advertising expenditures becoming more responsive to changes in real GDP, to changes in GDP price inflation, and to changes in nominal GDP? To that we next turn our attention.

\section{DISCUSSION}

Our time series analyses encompassing almost a half century indicates that beginning in the late 1990's nominal aggregate advertising spending in the U.S. has become more sensitive to changes in GDP. Along the way, we have urged that a high priority be given to developing media specific and aggregate price indices that could be used to distinguish between nominal and real changes in advertising outlays, and thereby advance understanding of the antecedents and consequences of short-term, cyclical, and secular shifts in U.S. GDP and its components.

The digital revolution stands as an exemplar of Schumpeter's "creative destruction" that has delivered extraordinary benefits to economies and societies around the world, even as it has also imposed seemingly incalculable costs everywhere. Of particular interest to the purposes at hand are the questions of whether and how the digital transformation presently underway in the advertising industry may have affected response measurement practices and agency-client relations in ways that can effect long-run changes in the size of the total advertising market and its composition with respect to the various media advertisers employ to reach their target audiences. Moreover, these evolving digital era practices and relationships have been accompanies by the reappearance of a number of fundamental issues about the processes and effects of advertising similar to those that have persisted since the early days of modern advertising (Fogg-Meade [1900]). Those issues include questions about the 
intrusiveness and function of advertising and the challenges that follow in assessing the nature and magnitude of its economic and social effects. In what follows, we consider implications of our results for the management of advertising campaigns and for looming antitrust policies affecting advertising. Each of these issues would benefit substantially from the availability of aggregate advertising and media-specific price indices.

\section{VII.1 Management of Advertising Campaigns}

The ascendancy of digital advertising has served to both "informate and automate" (Zuboff [1988],[2001]) the organizational planning and control systems surrounding the management of advertising campaigns and given rise to a "new era of marketing accountability, in which advertising 'budgets'... have turned into marketing 'investments'". 49 "Attribution" methods are now widely used in campaign planning and budgeting that utilize "big" data to target and track consumers over time on their "journeys" to purchase (Goldfarb and Tucker [2011], Goldfarb [2014]). Attribution analysis seeks to assign a weight to each "touchpoint" across all online and offline media to which a consumer is exposed prior to purchase. Such analyses are typically grounded in some form of a marketing mix model but the methods vary widely in terms of structure and data inputs. The introduction of "zero-based budgeting" has led marketing managers to believe they must "do more with less resources" and encouraged the practice of "managing what can be measured." 50 These developments have revived old suspicions about excessive "short-termism" in marketing decision-making (Lodish and Mela [2007]) and fueled new allegations that firms are overspending (Aaker and Carman [1989]) on media that can be shown to generate short-run response at the expense of investing more in other media better suited to long-term brand building (Binet and Field [2013]). The latter authors maintain:

"The way in which log-term effects are generated is fundamentally different from how most short-term effects are produced. Although long-term effects always produce some short-term effects the reverse is not true and long-term effects are not simply the accumulation of short-term effects." ${ }^{51}$

Recently, Danaher and van Heerde [2018] have shown analytically how reliance on attributions methods can misguide and distort the allocation of advertising funds across media.

\footnotetext{
49 Rapport [2015]. Also see Agrawal et al. [2020] and Bauer [2020].

50 Jacobs et al. [2018] and Butts et al. [2020].

${ }^{51}$ Binet and Field [2013, p. 9]. Also see Tiltman et al. [2019].
} 
Taking into account that current period advertising may carry over into future periods plus there may be interaction effects among advertising appearing in different media, Danaher and van Heerde demonstrate the attribution is proportional to the marginal effectiveness of a medium times its number of exposures. Accordingly, oft-used media will have high attribution weights. However, in the case of a time invariant profit maximizing allocation of a fixed budget, the optimal solution does not depend upon the number of times a consumer is exposed to a medium.

The state of knowledge about the processes and effects of advertising reflects the interplay between two different methodologies that aspire to measure the causal effects of advertising, and have come to be known by their short-hand labels as "Observational Studies" (OS) because they typically involve econometric analysis of time series data, and "Randomized Controlled Trials" (RCT). The growth of digital advertising has spurred notable advances in both streams of research and the healthy cross fertilization between them.

In an influential study, Lewis and Rao [2015] analyzed the results from 25 RCTs conducted between 2007 and 2011 with display advertising campaigns: 19 campaigns for five "well known" retailers and six campaigns for two financial service firms. The campaigns were of relatively short duration: the median campaign length was ten days for the retailers and 32 days for the financial service advertisers. Campaign costs involved outlays corresponding to "20-60 'premium' display ads," the equivalent of "7-10 prime time television commercials" (p. 1942). The experiments utilized individual-level measures of consumer purchase behavior, with the median campaign reaching over a million individuals. The experiments followed standard industry practice of defining the evaluation window over which purchase behavior was observed as "the number of time periods ads were running and a relative short window, 1-4 weeks, following the campaign" (p. 1955). In designing advertising field experiments, a critical tradeoff needed to be made between lengthening the evaluation window to capture long-lived response to ads, and the tendency for there to be a loss of statistical power to diminish as the evaluation window extends. Relative to great volatility of such data, Lewis and Rao characterized the effects on purchase behavior required for a campaign to be profitable as "very small," due to the estimates of the ROI for a campaign being "inherently imprecise" (p. 1942, emphasis added). Given the imprecision of the results, the authors note that the implied scale required for RCTs to yield unequivocal results was such to render them infeasible for many advertisers. 
Faced with the classic dilemma reminiscent of Lodish's [1986] memorably framing of the issue as one of choosing between being "vaguely right versus precisely wrong," advertisers turn to observational studies on the assumption they will yield "satisfactory", if fallible measurements. The dilemma is particularly vexing when the effects are "small," as in the case of online advertising, since it has been shown that correlated online behaviors ("activity bias") can lead to overestimates of the effects of advertising (Lewis, Rao, and Reiley [2011]). Gordon et al. [2019] report an empirical assessment of whether data typically available to analysts in the advertising industry when used in conjunction with statistical models for making causal inferences, is adequate to recover the results obtained from an RCT. The heart of the assessment is a detailed comparison of the results from 15 "big" advertising field experiments conducted at Facebook with those obtained by applying these methods for making causal inferences using the kind of data available in practice from observational studies. The study focuses on the estimation of "propensity scores" from observable measures used to control for differences between treated and untreated consumers. The set of 15 campaigns was selected to encompass a range of advertisers (retail, financial services, e-commerce, telecom, and tech) conducted during the first nine months of 2015. The authors conclude that "commonly used observational approaches based on the data usually available in the industry from observational studies often fail to accurately measure the true effect of advertising" (p. 193). However, this study is part of an ongoing research project investigating this issue with a larger sample of several hundred recent campaigns for which results from RCT studies are available to shed light on the conditions under which data from observational studies may suffice.

Meanwhile, Shapiro et al. [2020] have pursued a different path to developing a "generalizable and robust" set of results relating to the causal effect of television advertising on sales. The stated goal of developing generalizable results is to provide managers and policy makers with a prior distribution that will guide their decision making and recommendations relating to television advertising. Accordingly, the focus is on the full distribution of results, irrespective of their sign, size, or statistical significance, thereby circumventing the problem of publication bias that may plague meta-analysis studies.

A particularly noteworthy feature of the study is the use of a "border strategy" to address the identification problem that arises when advertising is not randomly assigned to geographical areas (Shapiro [2018]). The authors turn to the prevailing institutional 
arrangements that surround the buying of television advertising time to justify a plausibly random source of variation in exposure to advertising across geographical areas and over time. An extensive database was assembled from multiple sources consisting of the store level weekly brand sales (quantities and prices) and media purchases for four sources of television (network, cable, spot, and syndication). The latter information was matched to the Neilsen Designated Market Areas (DMA) and converted to exposure levels (i.e., Gross Rating Points) levels using audience size data. The database encompassed five years (2010-2014) of weekly sales and television advertising exposure levels for 288 brands of consumer purchased packaged goods that collectively accounted for approximately 10 percent of consumer expenditures. For each brand, the authors estimated a constant elasticity model where the quantity sold in a particular store and week is a function of vectors of own and competitor prices and advertising, where advertising is a stock variable to capture carryover effects. The median of the estimated distribution of long-run elasticities was 0.014 and more than two-thirds of estimates were not statistically different from zero. Moreover, for more than two-thirds of the brands the return on investment in advertising for a given week was negative at the margin, indicating that the majority of brands overinvested in advertising. The authors caution: "This result does not imply that all advertising is wasted. For many brands, the observed level of advertising is more profitable than no advertising at all" (p.4).

To assess the robustness of the estimates, Shapiro et al. [2020] analyzed the sensitivity of the results to both the assumptions underlying the selection of the data used in estimation and the identification strategies essential to support the claim of causality based on observational data. The findings were affirmative and in line with Chan and Perry's [2017] call for the development of media mix models that "acknowledge the uncertainty in the modeling process and the need for transparency between the modeler and the end user of the model results."(p.2). As a result of privacy regulation and decisions by browsers, digital advertising faces a future without cookies. Intermedia competition has grown over time and the longestablished structure of "up front" and "spot" markets for television advertising is currently in a state of flux. Accordingly, media-mix budgeting practices can be expected to continue to evolve to meet the dynamic demands of decision makers in the digital era. The role of media mix models and RCTs are often juxtaposed against one another as imperfect substitutes for each other. Note that in the context of media mix models, the availability of media-specific advertising price indices is critical. 
Kolsarici et al. [2020] have recently proposed a "bounded rationality" theory of advertising budgeting whereby advertising spending is the outcome of a decision process that reflects a combination of both heuristics and analytical reasoning. Whereas descriptive studies of advertising budgeting have traditionally emphasized the role of heuristics in budget setting (e.g., advertising/sales norms for a product category), Kolsarici et al. argue that managers also to seek to cope with the uncertainty about the effectiveness of their advertising programs inherent in a dynamic operating environment. The pioneering work of Little ([1966],[1977]) and others on adaptive experimentation and control theory provides the rationale for hypothesizing that experimentation should be proportional to the uncertainty about advertising effectiveness. ${ }^{52}$ To test the implications of their theory, Kolsaric et al. conducted an empirical study using time series data for eight brands from three product categories (durable and non-durable) and at different stages of their life cycles. The results show that advertising budgeting is highly brandspecific, sensitive to different heuristics and changes in advertising effectiveness, and are consistent with the general proposition that advertising budgeting should be viewed as an "intendedly rational" decision process (Simon [1957]) in the sense that over time managers appear to adjust advertising outlays in response to uncertainty surrounding advertising effectiveness. The perspective that the advertising budget is an instrument that managers in organizations with a wide variety of objectives employ to adapt to dynamic, competitive environments is one that warrants further development and testing.

\section{VII.2 Public Policy}

Moving to the public policy domain, one finds that the digital era has given rise to a host of larger unresolved issues likely to challenge the future organization of the advertisingsupported media industry. Working within the paradigm of industrial economics, Gordon et al. [2020] have recently enumerated a set of policies and practices alleged to be sources of "allocative inefficiencies" in digital markets. Gordon et al. [2020] identify four such sources of inefficiencies: measurement of advertising response, organizational "frictions" affecting relations within and among firms comprising the industry's vertical structure, ad blocking, and

\footnotetext{
${ }^{52}$ Early analyses on the economics of advertising make the simplifying assumption that market response to advertising was certain (Schmalensee [1972], p. 32). Horowitz [1970] explored introducing uncertainty into a simple advertising model but the subsequent investigation by Dehavez and Jacquemin [1975] found that incorporating the combined impact of uncertainty and dynamic conditions (e.g., carryover effects) was unworkable.
} 
brand safety. These developments have stimulated a major debate as to whether antitrust policy needs to undergo a fundamental reform in order to address competition issues related to the digital economy. ${ }^{53}$

Woodcock [2018], for example, has argued that the internet has rendered the information function of most advertising obsolete. He further contends that applying antitrust laws already in place a half century ago, U.S. courts had previously ruled that persuasive advertising was anticompetitive. However, in Woodcock's telling, those rulings were not widely enforced by the Federal Trust Commission for "fear of depriving consumers of advertising's information value" (p. 2270). Khan [2017] has taken the taken a quite different position, maintaining that the current antitrust paradigm where competition is linked to consumer welfare is "unequipped to capture the architecture of market power in the modern economy" (p. 710). Rather than attempting to protect consumer privacy by regulating the business models of platform companies, Romer [2019] has proposed that the revenue platform companies earn from the sale of targeted advertising be taxed. Such a policy presumably "would encourage platform companies to shift toward a healthier, more traditional model."

In an analyses of public policy issues surrounding the future of advertising-supported media. Mandel [2019] has also undertaken an analysis of the advertising share of nominal U.S. GDP. Among other things, he reported that in recent years the growth in ad spending in the U.S. has "broken out of the long- term trend and in the period 2010-2018 averaged less than 1 percent of nominal GDP" (p. 5). Referring to data for the BLS's media price indices, he goes on to argue that this trend could be explained by the substantial concomitant decline that has occurred in the price of digital advertising relative to that for traditional media. As a result, he posits price competition in the advertising market has risen over time and contributed to the ascendancy of digital media.

The above discussion is not intended to be a comprehensive survey of public policy issues related to advertising, but it does serve to illustrate the range of contemporary yet longstanhding policy issues that would benefit from the availability of media-specific and aggregate advertising price indices. In addition, distinguishing between nominal and real growth

\footnotetext{
${ }^{53}$ While the focus of this paper has been on the U.S. advertising market, the availability of media price indices for other advertising markets would be valuable to research concerned with cross-national differences in the intensity and effectiveness of advertising. See, for example, Jones [1990], Deleersynder et al. [2009], and Steenkamp et al. [2011].
} 
in the advertising and marketing services industry could add to the body of evidence Nakamura [2020] and others have been accumulating in connection with the investigation of the measurement and growth and prices in the $21^{\text {st }}$ century.

\section{CONCLUDING REMARKS}

The research question posed at the outset of this research project was: Does the U.S. advertising industry have a growth problem, a measurement problem, or both? Our most important empirical finding is that the elasticity of advertising with respect to Gross Domestic Product appears to have increased over the period of the late 1990's through 2018-from approximately 1.4 to 1.9. Such a date precedes the onslaught to the pandemic and therefore precludes the effects that COVID 19 has had on GDP and advertising spending. Nonetheless, the evidence that over time aggregate advertising spending in the U.S. has become more sensitive to the overall performance of the national economy is clearly both provocative and tentative.

It is obvious that much remains to be done to develop data bases to support econometric analyses that will advance our capabilities to assess and understand structural shifts in macroeconomic relationships between aggregate advertising activity and the performance of the economy of which it is a part. Toward that end, we have advocated collection of data on media-specific media prices that would enable nominal advertising spending to be converted to real advertising spending. If this research project stimulates such a development, it will have served a valuable purpose.

Document Name: Aggregate Advertising Expenditures in the US Economy V19

Document Date: 22 November 2020 


\section{References}

Aaker, David A. and James M. Carman [1989], “Are You Over Advertising?” Journal of Advertising Research, 22 (August/September), 57-70.

Arrow, Kenneth J., George G. Stigler, Elisabeth M. Landes, and Andrew M. Rosenfield [1990], "Economic Analysis of Proposed Changes in the Tax Treatment of Advertising Expenditures," The Advertising Tax Coalition, unpublished paper, Chicago, IL: Lexecon Inc., August. Available at: https://www.scribd.com/document/27267813/Economic-Analysis-of-Proposed-Changes-in-theTax-Treatment-of-Advertising-Expenditures.

Arzaghi, Mohammad, Ernst R. Berndt, James C. Davis, and Alvin J. Silk [2012], "The Unbundling of Advertising Services: An Economic Analysis," Review of Marketing Science, 10 (Article 4), 1-53. Bachman, Jules [1967], Advertising and Competition, New York: New York University Press.

Baine, Derek [2019], "Advertising Market Growth Unable to Keep up with GDP," January 30.New York: S\&B Global, Market Intelligence. Available at:

https://platform.mi.spglobal.com/web/client?auth=inherit\#news/article?KeyProductLinkType=2 $\underline{\& i d=49482900}$

Bauer, Thomas, Julie Boudet, Michael Lamb, and Kelsey Robinson [2020], “Performance Branding and How It Is Reinventing Marketing ROI," June 15. Available at:

https://www.mckinsey.com/business-functions/marketing-and-sales/our-insights/performancebranding-and-how-it-is-reinventing-marketing-roi?cid=other-eml-alt-mipmck\&hlkid=c8aeb0778f7345f4b4c30be9079198cc\&hctky=2427140\&hdpid=cd049d48-afe2$\underline{477 e-a 8 a 3-90 f 68 e 32 b 77 b}$

Beach, Charles M. and James G. MacKinnon [1978], "Full Maximum Likelihood Estimation of Second-Order Autoregressive Error Models", Journal of Econometrics 7:187-198.

Binet, Les and Peter Field [2017], The Long and the Short of It: Balancing Short and Long-Term Marketing Strategies. London: Institute of Practitioners in Advertising, June.

Blank, David M. [1963], "A Note on the Golden Age of Advertising," Journal of Business, 36 (January), 33-38. 
Borden, Neil H. [1944], The Economic Effects of Advertising. Chicago: Richard D. Irwin. Especially Chapter 3, "The Economic Importance of Advertising as Measured by Expenditures," pp. 53-62.

Bureau of Labor Statistics (BLS) [not dated], BLS Handbook of Methods, ch. 14, "Producer Prices", 16 pp.

Bureau of Labor Statistics [2020], Producer Price Index Detailed Report, June. Available online https://www.bls/gov/ppi/ppidr202006.pdf.

Burton, Joe [2009], “A Marketer's Guide to Understanding the Economics of Digital Compared to Traditional Advertising and Media Services." New York: American Association of Advertising Agencies.

Byrne, David M., John G. Fernald, and Marshall B. Reinsdorf [2016], “Does the United States Have a Productivity Slowdown or a Measurement Problem? Finance and Economics Discussion Series 2016-017. Washington: Board of Governors of the Federal Reserve System. Available at: http://dx.doi.org/10.17016/FEDS.2016.017

Campbell, Donald T. and Donald K. Fiske [1959], "Convergent and Discriminant Validation by the Multitrait-Multimethod Matrix," Psychological Bulletin, 56 (March), 81-105.

Chemi, Eric [2014], “Advertising's Century of Flat-Line Growth,” Bloomberg News, March 3.

Available at: https://www.bloomberg.com/news/articles/2014-03-03/advertisings-century-offlat-line-growth

Comanor, William S. and Thomas A. Wilson [1974], Advertising and Market Power. Cambridge, MA: Harvard University Press.

Coyle, Diane and Leonard Nakamura [2019], "Toward a Framework for Time Use, WelfareCentric Economic Measurement," Working Paper 19-11, Federal Reserve Board of Philadelphia, February. Available at: https://doi.org/10.21799/frbp.wp.2019.11.

Danaher, P. J., \& van Heerde, H. J. [2018]. “Delusion in attribution: caveats in using attribution for media budget allocation, Journal of Marketing Research, 55(5), 667-6 66.

Dehez, Pierre and Akex Jacquemin [1975], “A Note on Advertising Policy Under Uncertainty and Dybanic Conditions," Journal of Industrial Economics, 23 (September), 73-78. 
Deleersynder, Barbara, Markin G. Dekimpe, Jean-Benedict E.M. Steenkamp, and Peter S.K. Leeflang [2009], "The Role of National Culture in Advertising's Sensitivity to Business Cycles: An Investigation Across Countries," Journal of Marketing Research, 46 (October), 623-636.

Diewert, W. Erwin [1978], "Superlative Index Numbers and Consistency in Aggregation", Econometrica, July, 46(4):883-900.

Diewert, W. Erwin [2015], "Two Stage Aggregation and Homogeneous Weak Separability", ch. 9 in Diewert, Index Number Theory and Measurement Economics, Vancouver, B.C.: University of British Columbia, Vancouver School of Economics, unpublished lecture notes, February.

Diewert, W. Erwin and Kevin J. Fox [2020], "Measuring Real Consumption and CPI Bias under Lockdown Conditions", Vancouver B.C.: University of British Columbia, Vancouver School of Economics, unpublished manuscript, April 13.

Ehrlich, Isaac and Lawrence Fisher [1972], "The Derived Demand for Advertising: A Theoretical and Empirical Investigation", American Economic Review, 72(3):366-388.

Evans, David S. [2008], "The Economics of the Online Advertising Industry," Review of Network Economics, 7 (September), 351-391.

Evans, David S. [2009], "The Online Advertising Industry: Economics, Evolution, and Privacy," Journal of Economic Perspectives, 23 (September), 37-60.

Fogg-Meade, Emily [1901], "The Place of Advertising in Modern Business," Journal of Political Economy, 9 (March), 218-242.

Fisher, Lawrence, and Isaac Ehrlich [1984], "A New Price Index for Advertising in the United States", unpublished manuscript.

Goldfarb, Avi [2014], "What Is Different About Online Advertising?" Review of Industrial Organization, 44 (2), 115-129.

Goldfarb, Avi and Catherine Tucker [2019], “Digital Economics," Journal of Economic Literature, 57(1), 3-43. 
Gordon, Brett, Florian Zettelmeyer, Neha Bhargava, and Dan Chapsky ]2019], "A Comparison of Approaches to Advertising Measurement: Evidence from Big Field Experiments at Facebook," Marketing Science, 38 (2), 193-225.

Gordon, Brett R., Kinshu Jerath, Zsolt Katona, Sridhar Narayanan, Jiwoong Shin, and Kenneth C. Wilbut [2020], "Inefficiencies in Digital Advertising Markets," Journal of Marketing, forthcoming. Griliches, Zvi [1992], "Introduction” in Griliches, Zvi, Ernst R. Berndt, Timothy F. Bresnahan, and Marilyn E. Manser, eds., Output Measurement in the Service Sector. Chicago: University of Chicago Press.

Guptam, Sunil and Joseph Davin [2019], Digital Marketing. Boston, MA: Harvard Business School Publishing, December 19.

Hall, Robert E. [2012], "The Cyclical Response of Advertising Refutes Counter-Cyclical Profit Margins in favor of Product-Market Frictions", Cambridge, MA: National Bureau of Economic Research, Working Paper 18370, September.

Hall, Robert E. [2014], "What the Cyclical Response of Advertising Reveals about Markups and Other Macroeconomic Wedges", Stanford, CA: Stanford University, Hoover Institution and Department of Economics, unpublished manuscript, April 23.

Internal Revenue Service [2012], Statistics of Income 2012: Corporate Income Tax Returns. Washington, D.C.: U.S. Department of the Treasury, Internal Revenue Service. Internal Revenue Service [1962], "Statistics of Income 1960-61: U.S. Business Tax Returns," Washington DC: U.S. Treasury Department, Internal Revenue Service, Publication No. 438 (6$62)$.

Internet Advertising Bureau [2019], “Internet Advertising Revenue Report: 2018 Full Year Results," May. Available at: https://www.iab.com.

Internet Advertising Bureau [2020], “Internet Advertising Revenue Report: Full Year 2019 Results and Q1 2020 Revenues," May. Available at: https://www.iab.com.

Jones, John P. [1990], "Advertising: Strong Force or Weak Force: Two Views and Ocean Apart," International Journal of Advertising, 9, 233-246. 
Juenger, Todd, Jason Park and Nataliya Nedzhvetskaya [2016], “The Long View: U.S. Media:

Revisiting the Graveyard Four Years On-- Not So Funny Anymore." New York: Bernstein Research, April 7.

Kolsarici, Ceren, Demetrios Vakrasats, and Prasad A. Naik [2020],"The Anatomy of the Advertising Budget Decision: How Analytics and Heuristics Drive Sales Performance," Journal of Marketing Research,57 (3), 468-488.

Kossar, Kevin R. [2014], “Advertising by the Federal Government: An Overview," unpublished paper, Congressional Research Service, Washington, D.C., June 23.

Available at: https://fas.org/sgp/crs/misc/R41681.pdf

Letang, Vincent and Michael Leszega [2017],"U.S. Advertising Forecast: Executive Summary," Magna Global, New York, March.

MacKinnon, James G. [1996], “Numerical Distribution Functions for Unit Root and Cointegration Tests", Journal of Applied Econometrics, November/December, 11(6):601-618.

Magna Global [2015], “U.S. Media Forecasts: Definitions and Methodology,” July.

Available from: http://www.magnaglobal.com.

Mandel, Michael [2019], "The Declining Cost of Advertising: Policy Implications," Progressive Policy Institute, Washington, D.C., July. Available at:

https://www.progressivepolicy.org/issues/government-reform/the-declining-price-ofbadvertising-policy-implications-2/

Mandese, Joe [2007], “The Thinking Person's Guide to Media: Chapter One: What is Advertising Anyway? MediaPost, February 27. Available at:

http://www.mediapost.com/publications/article/56253.

Mandese, Joe [2009a], “Bottoms Up: Interpublic Revises Forecast Model, Sifts to 'Top-Down,' Media-Centric Approach," Media Daily News, (July 10). Accessed at:

http://www.mediapost.com/publications/article/109547/.

Mandese, Joe [2009b], "Costly Decision: Interpublic Scraps Media Inflation Index," Media Daily News," (July 13). Accessed at: 


\section{http://www.mediapost.com/publications/article/109625/costly-decision-interpublic-scraps-}

$\underline{\text { media-inflation/ }}$

McAlister, Leigh, Raj Srinivasan, Niket Jindal, and Alberta A. Cannella [2016], “Advertising

Effectiveness: The Moderating Effect of Firm Strategy," Journal of Marketing Research, 53

(April), 207-224.

Myers, Kenneth H. [1958], "Have We A Decline in Advertising Appropriations?" Journal of Marketing, 23 (April), 370-375.

Myers, Kenneth H. [1962], “Is Advertising a Growth Industry?” Media/Scope, (June), 35-41.

Nakamura, Leonard I. [2020], "Evidence of Accelerating Mismeasurement of Growth and

Inflation in the U.S. in the21st Century," Working Pape 20-41, Research Dept., Federal Reserve Bank of Philadelphia, October.

National Bureau of Economic Research [2016], "US Business Cycle Expansions and Contractions," Cambridge, MA, February 24. Available at: http://www.nber.org.cycles/.

Phillipson, Guy [2016], “IAB's Guy Phillipson: 'Ad industry's transformation has only just begun'," Campaign (September 5). https://www.campaignlive.co.uk/article/iabs-guy-phillipson-adindustrys-transformation-just-begun/1407492

Pindyck, Robert S. and Daniel L. Rubinfeld [1998], Econometric Models and Economic Forecasts, Fourth ${ }^{\text {h }}$ edition, Boston, MA: Irwin McGraw-Hill.

Quantitative Micro Software, EViews7 V9 User's Guide II, Irvine, CA: Quantitative Micro Software [1994-2009]. www.eviews.com.

Pope, Daniel [1983], The Making of Modern Advertising. New York: Harper.

Rapport, Jeffrey F. [2015], “Is Programmatic Advertising The Future of Marketing?" Harvard Business Review (Website), June 22. Available at:

https://www.hbs.edu/faculty/Pages/item.aspx?num=49520

Rogers, Richard T. and Robert J. Tokle [1995], "The Economics of Advertising: Where's the Data?" Review of Industrial Organization, 10 (6), December, 675-687.

Schmalensee, Richard [1972], The Economics of Advertising, New York: North-Holland. 
Schultz, Donald [2016], "The Future of Advertising or Whatever We're Going to Call It," Journal of Advertising, 45(3), 276-285.

Sherman, Sidney A. [1900], "Advertising in the United States," Journal of the American Statistical Association, 7 (December), 1-44.

Shi, Huanhuan, Rajdeep Grewal, and Shrihari Sridhar [2017], "Organizational Herding in Advertising Spending Disclosures: Evidence and Mechanisms," UNC Kenan-Flagler Business School, Mays Business School Research Paper No. 3071616, November 15. Available at: https://ssrn.com/abstract=3071616.

Silk, Alvin J. [2012], "Conflict Policy and Advertising Agency-Client Relations: The Problem of Competing Clients Sharing a Common Agency," Foundations and Trends in Marketing, 6(2). Hanover, MA: now Publishers Inc.

Silk Alvin J., Lisa R. Klein and Ernst R. Berndt [2001], "The Emerging Position of the Internet as an Advertising Medium," Netnomics, 3 (September), 129-148.

Silk, Alvin J., Lisa R. Klein and Ernst R. Berndt [2002], "Intermedia Substitutability and Market Demand by National Advertisers," Review of Industrial Organization, 20 (June), 323-348.

Silk, Alvin J. and Charles King III [2013], "How Concentrated is the Advertising and Marketing Services Industry? Myth vs. Reality," Journal of Current Issues and Research in Advertising, 34 (1), 166-193. Available at: https://www.tandfonline.com/doi/pdf/10.1080/10641734.2013.754721

Silk, Alvin J. and Marta S. Stiglin [2016], "Build It, Buy It, or Both? Rethinking the Sourcing of Advertising Sources," International Journal of Marketing Studies, Vol 8, No. 1 (February).

Simon, Julian [1970], Issues in the Economics of Advertising. Urbana, IL: University of Illinois Press

Standard and Poor's COMPUSTAT User's Guide [2003]. New York: McGraw-Hill. Available at: http://sites.bu.edu/qm222projectcourse/files/2014/08/compustat users guide-2003.pdf 
Steenkamp, Jan-Benedict E.M. and Eric (ER) Fang [2011], "The Impact of Economic Contractions on the Effectiveness of R\&D and Advertising: Evidence from U.S. Companies Spanning Three Decades," Marketing Science, 30 (July-August), 628-645.

Telser, Lester G. [1964], “Advertising and Competition,” Journal of Political Economy, 72 (December), 537-562.

Telser, Lester G. [1968], "Some Aspects of the Economics of Advertising,” Journal of Business, 41 (April), 166-173.

Vakratssas, Demetrios, and Tim Ambler [1999], "How Advertising Works: What Do We Really Know?" Journal of Marketing, 63 (January), 26-43.

Wieser, Brian [2019], “Digital Deceleration Deciphered," Group M, (May 5), New York. Available at: https://www.groupm.com/news/digital-deceleration-deciphered.

Yang, Charles [1962], A Theoretical and Empirical Investigation of Advertising Cycles, unpublished Ph.D. Thesis, Graduate School of Business Administration, New York University.

Zuboff, Shoshana [1988]. In the Age of the Smart Machine: The Future of Work and Power. New York: Basic Books, 1988.

Zuboff, Shoshana [2001], "Automate/Informate: The Two Faces of Intelligent Technology," Organizational Dynamics, 14 (Autumn), 5-18. 
FIGURE 1

VERTICAL STRUCTURE OF THE U.S. ADVERTISING INDUSTRY

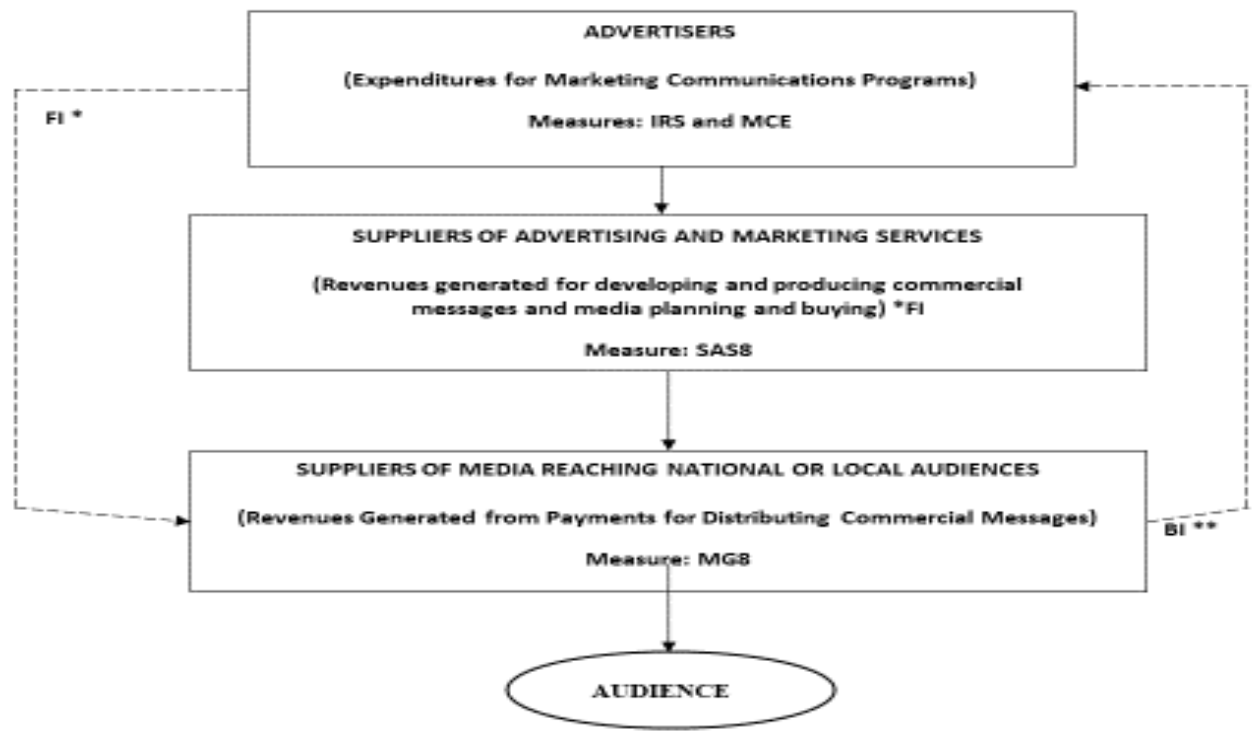

FI: Forwand Integration by Advertiser

BI: Backward integration by Media Supplier 
Figure 2a

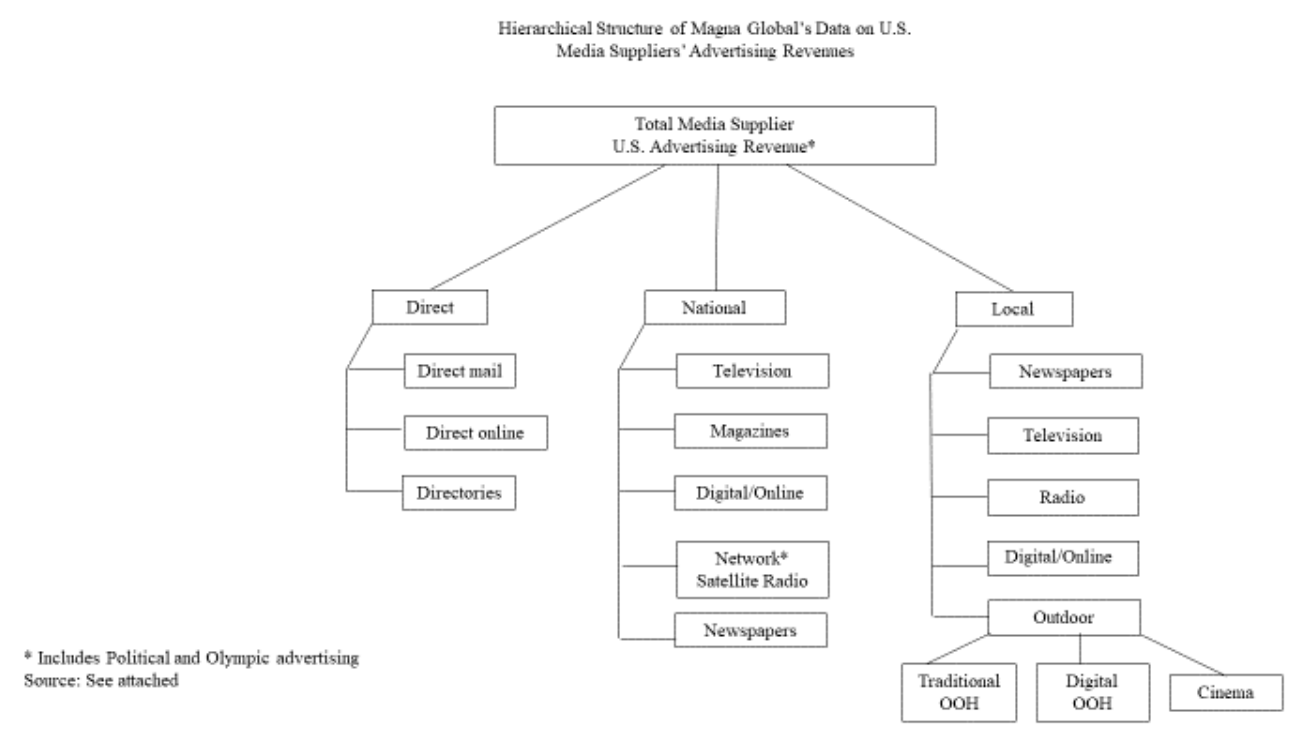

Figure $2 \mathrm{~b}$

Hierarchical Structure of Digital Media

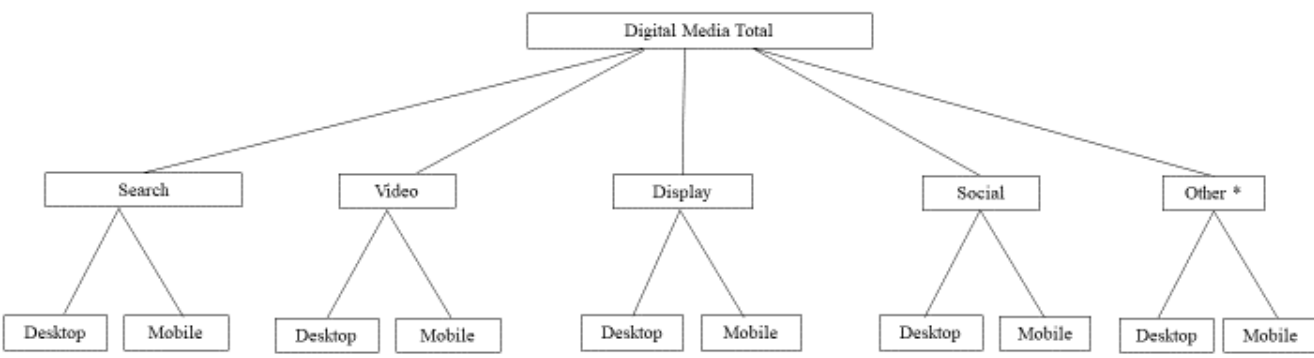

- Other: Lead Generation, Classified, and Email

Source: Magna Global Detailed Forecast Model 
Figure 3

Measures of Nominal Output for the U.S. Advertising Industry: 1960-2018 (Current \$Billion)

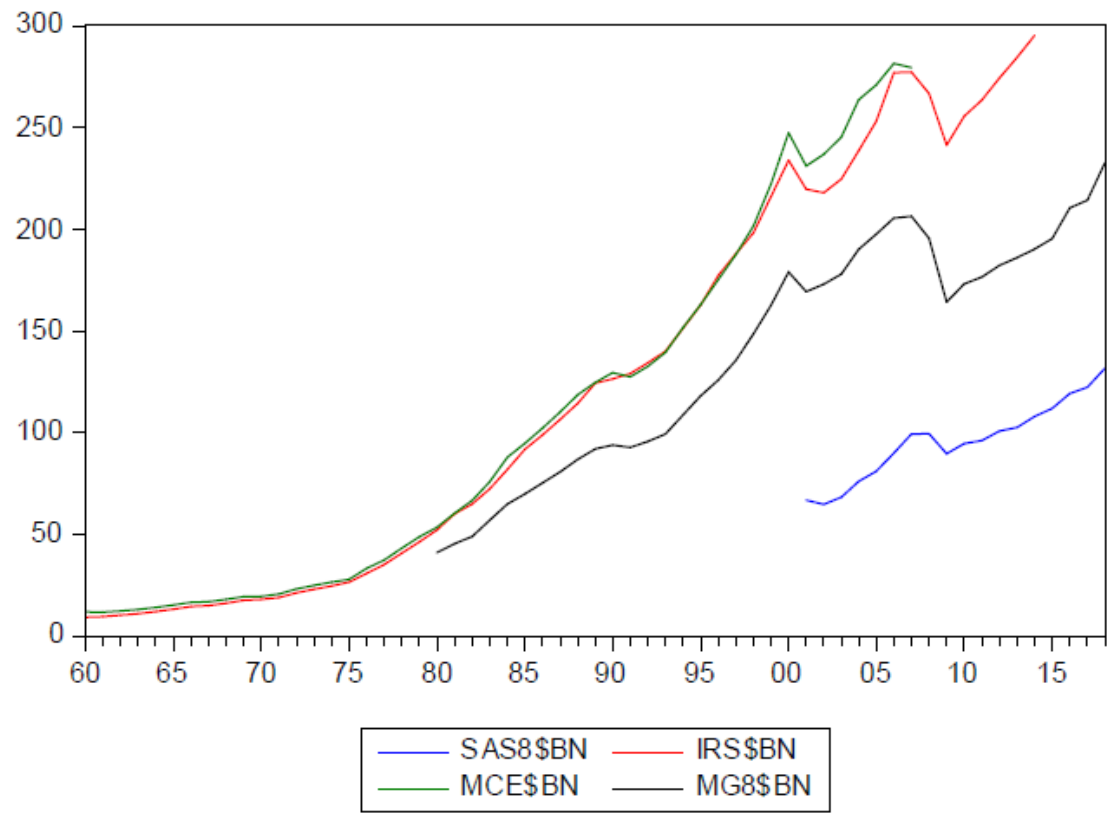

Figure 4

Shares (\%) of MG8 Media Supplier Receipts for 4 Major Advertisinig Media: 1980-2018 Current\$

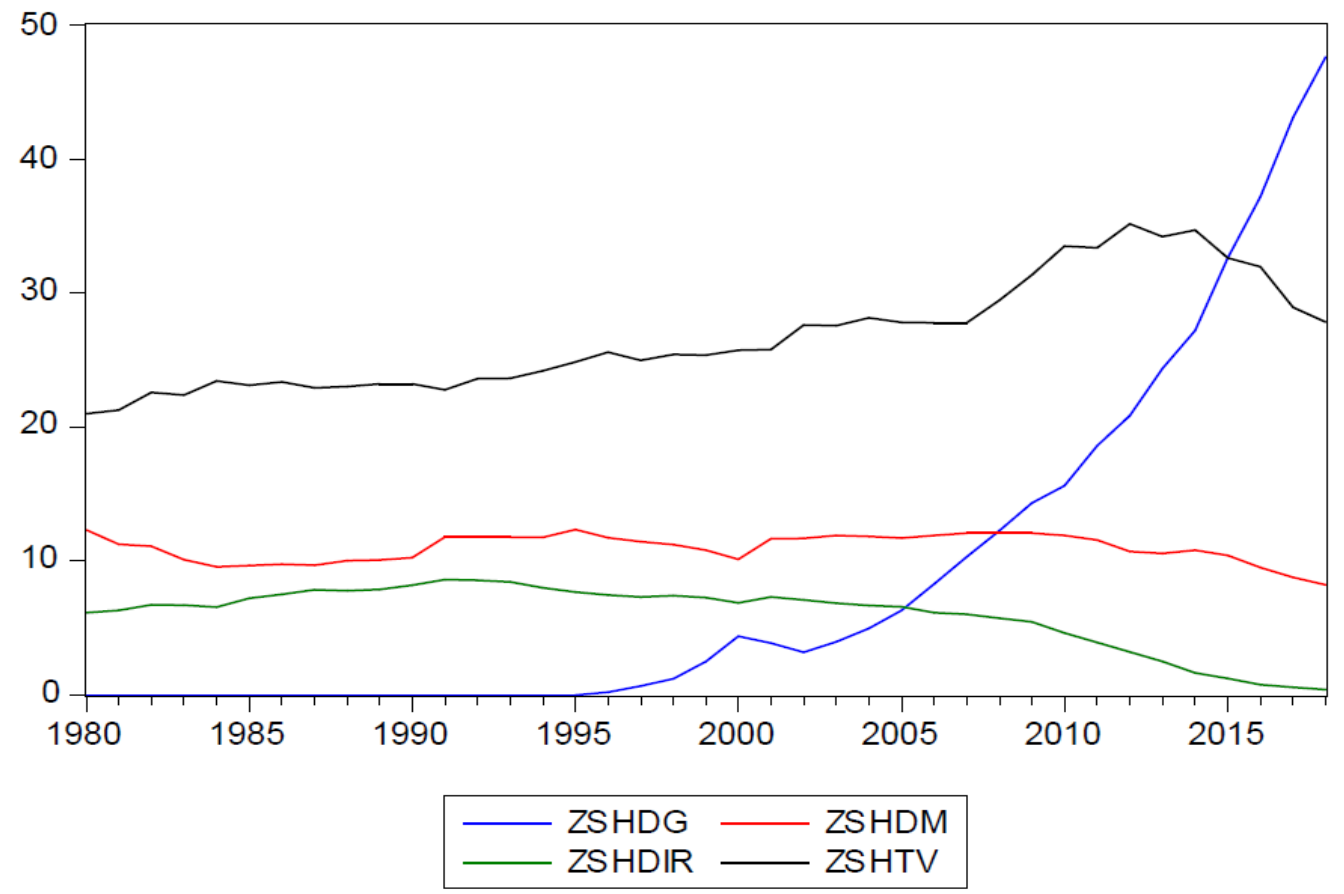




\section{Figure 5}

Shares (\%) of MG8 Media Supplier Receipts for 4 Minor Advertising Media: 1980-2018,Current \$

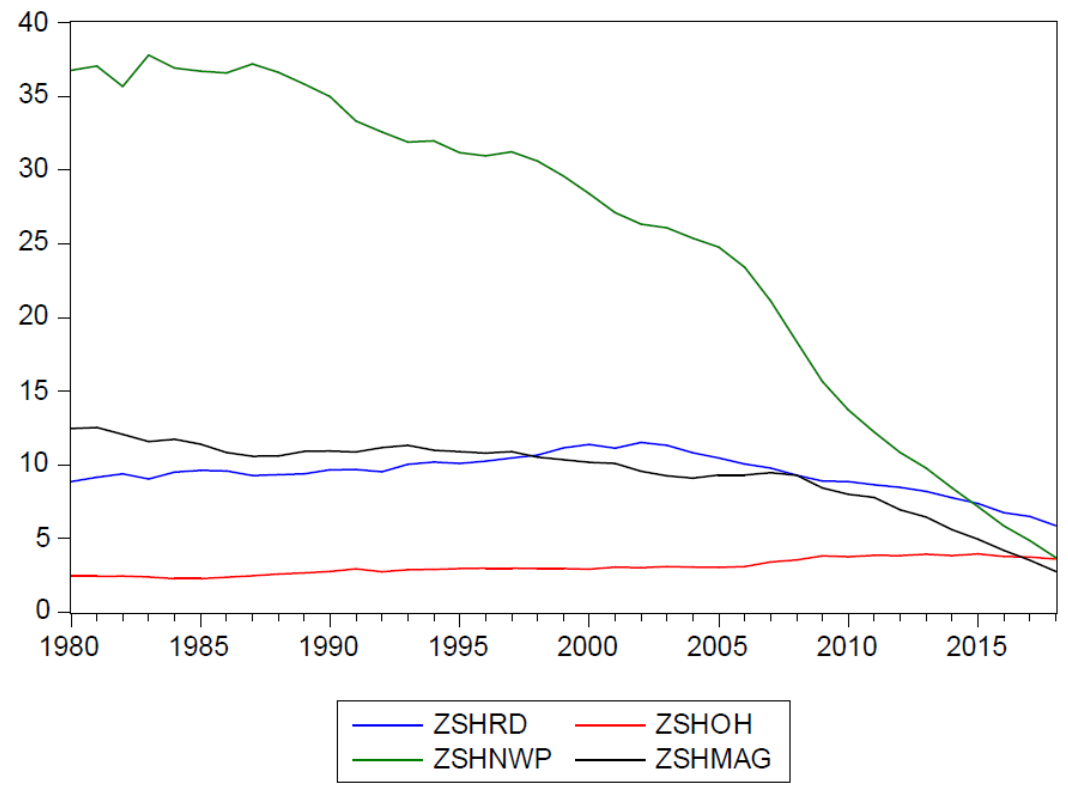

FIGURE 6: Comparison of MCE Composite Media Advertising CPMs, BLS Producer Price Index for Finished Goods, and BEA GDP Implicit Price Deflator: 1960-2006.

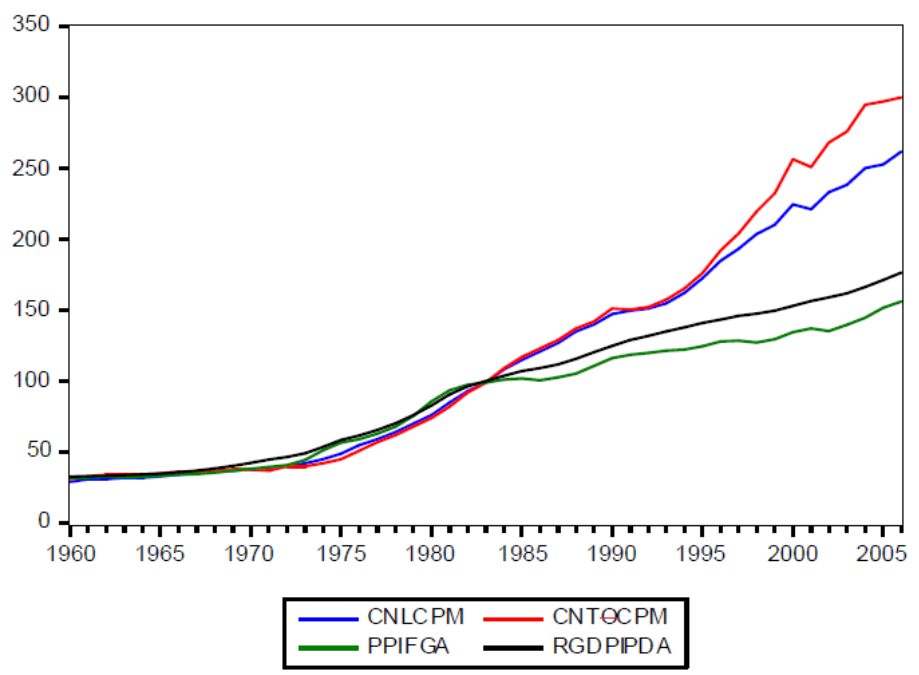


Figure 7

Partial Hierarchical Structure of BLS' Advertising Price Indices

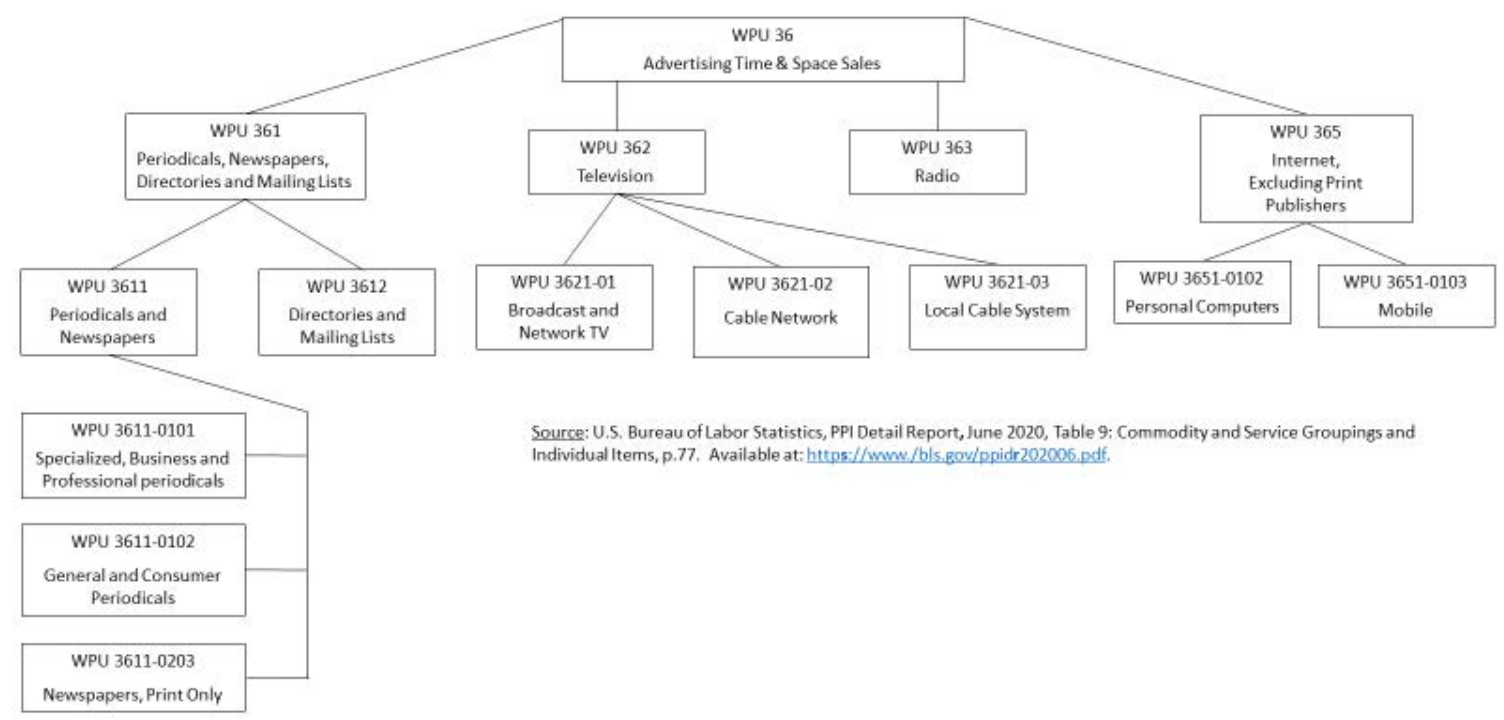


Figure 8: Correlograms of Log-Level (top panel) and Log First Differenced (bottom panel) Nominal Advertising Expenditures McCann-Erickson (left) and Internal Revenue Service (right)

Correlogram of LGMCE\$BN

\begin{tabular}{|c|c|c|c|c|c|c|}
\hline \multicolumn{7}{|c|}{$\begin{array}{l}\text { Date: } 09 / 03 / 20 \text { Time: } 17: 12 \\
\text { Sample: } 19602007 \\
\text { Included observations: } 48\end{array}$} \\
\hline Autocorrelation & Partial Correlation & & $A C$ & PAC & Q-Stat & Prob \\
\hline 10 & 12 & 1 & 0.952 & 0.952 & 46.233 & 0.000 \\
\hline$i=$ & $1 \longdiv { 1 }$ & 2 & 0.898 & -0.079 & 88.301 & 0.000 \\
\hline$i=$ & 171 & 3 & 0.842 & -0.046 & 126.15 & 0.000 \\
\hline 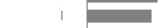 & 11 & 4 & 0.785 & -0.048 & 159.77 & 0.000 \\
\hline 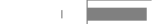 & 111 & 5 & 0.728 & -0.030 & 189.33 & 0.000 \\
\hline $1=$ & 11 & 6 & 0.670 & -0.042 & 214.95 & 0.000 \\
\hline 10 & 11 & 7 & 0.611 & $\begin{array}{l}-0.042 \\
-0.041\end{array}$ & 236.77 & 0.000 \\
\hline$\square$ & 101 & 8 & 0.547 & -0.091 & 254.70 & 0.000 \\
\hline 10 & 11 & 9 & 0.484 & -0.021 & 269.12 & 0.000 \\
\hline 10 & 11 & 10 & 0.423 & -0.027 & 280.40 & 0.000 \\
\hline 1 & 10 & 11 & 0.360 & -0.060 & 288.81 & 0.000 \\
\hline 10 & 111 & 12 & 0.297 & -0.045 & 294.70 & 0.000 \\
\hline 10 & 11 & 13 & 0.237 & $\begin{array}{l}-0.025 \\
-0.025\end{array}$ & 298.54 & 0.000 \\
\hline i & 11 & 14 & 0.177 & -0.038 & 300.76 & 0.000 \\
\hline 10 & 11 & 15 & 0.119 & -0.037 & 301.79 & 0.000 \\
\hline 151 & 101 & 16 & 0.061 & -0.057 & 302.07 & 0.000 \\
\hline 11 & 11 & 17 & 0.006 & -0.018 & 302.07 & 0.000 \\
\hline 1 & 11 & 18 & -0.048 & -0.050 & 302.26 & 0.000 \\
\hline $1=$ & 171 & 19 & -0.100 & -0.027 & 303.08 & 0.000 \\
\hline 1 至 1 & 111 & 20 & -0.148 & -0.036 & 304.96 & 0.000 \\
\hline
\end{tabular}

Correlogram of LGIRS\$BN

\begin{tabular}{|c|c|c|c|c|c|c|}
\hline \multicolumn{7}{|c|}{$\begin{array}{l}\text { Date: } 09 / 03 / 20 \text { Time: } 17: 06 \\
\text { Sample: } 19602007 \\
\text { Included observations: } 48\end{array}$} \\
\hline Autocorrelation & Partial Correlation & & $\mathrm{AC}$ & PAC & Q-Stat & Prob \\
\hline 1 & $1=$ & 1 & 0.948 & 0.948 & 45.894 & 0.000 \\
\hline 10 & 11 & 2 & 0.892 & -0.065 & 87.421 & 0.000 \\
\hline 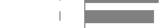 & 111 & 3 & 0.837 & -0.024 & 124.76 & 0.000 \\
\hline 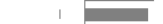 & 111 & 4 & 0.780 & -0.041 & 157.97 & 0.000 \\
\hline $1=$ & 11 & 5 & 0.724 & -0.031 & 187.21 & 0.000 \\
\hline 10 & 11 & 6 & 0.667 & -0.034 & 212.66 & 0.000 \\
\hline 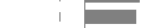 & 11 & 7 & 0.609 & -0.048 & 234.38 & 0.000 \\
\hline 10 & 101 & 8 & 0.547 & -0.081 & 252.31 & 0.000 \\
\hline 10 & 17 & 9 & 0.485 & -0.032 & 266.76 & 0.000 \\
\hline 15 & 111 & 10 & 0.424 & -0.031 & 278.11 & 0.000 \\
\hline 10 & 101 & 11 & 0.361 & -0.060 & 286.57 & 0.000 \\
\hline 10 & 11 & 12 & 0.298 & -0.053 & 292.48 & 0.000 \\
\hline ( & 11 & 13 & 0.237 & -0.025 & 296.33 & 0.000 \\
\hline । $\mathbf{\sigma}$ & 11 & 14 & 0.177 & -0.040 & 298.53 & 0.000 \\
\hline 10 & 11 & 15 & 0.118 & -0.039 & 299.54 & 0.000 \\
\hline 151 & 101 & 16 & 0.059 & -0.051 & 299.81 & 0.000 \\
\hline 111 & 111 & 17 & 0.003 & & 299.81 & 0.000 \\
\hline 1 - 1 & $1 \rrbracket 1$ & 18 & -0.051 & -0.035 & 300.02 & 0.000 \\
\hline $1=$ & 11 & 19 & -0.103 & -0.034 & 300.89 & 0.000 \\
\hline 1 . & 111 & 20 & -0.151 & -0.026 & 302.84 & 0.000 \\
\hline
\end{tabular}

Correlogram of MCENG

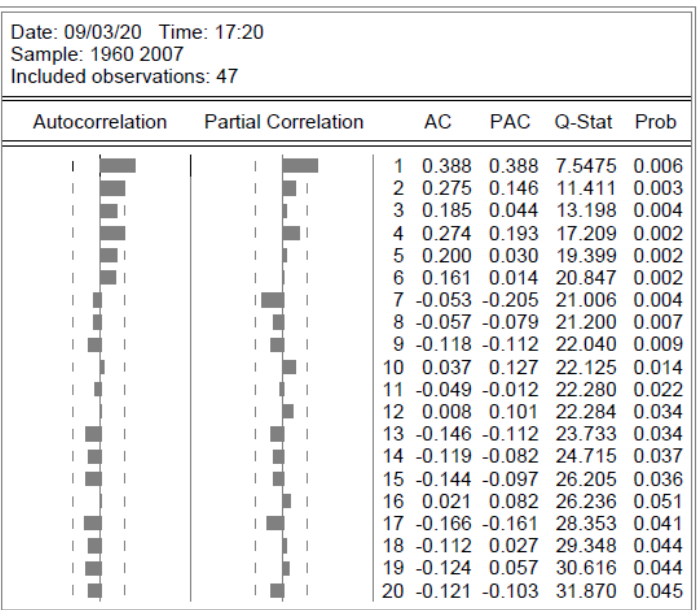

Correlogram of IRSNG

\begin{tabular}{|c|c|c|c|c|c|c|c|c|}
\hline \multicolumn{9}{|c|}{$\begin{array}{l}\text { Date: 09/03/20 Time: } 16: 58 \\
\text { Sample: } 19602007 \\
\text { Included observations: } 47\end{array}$} \\
\hline \multicolumn{2}{|c|}{ Autocorrelation } & \multicolumn{2}{|c|}{ Partial Correlation } & & $A C$ & \multirow{2}{*}{$\begin{array}{l}\text { PAC } \\
10.501\end{array}$} & \multirow{2}{*}{$\begin{array}{l}\text { Q-Stat } \\
12.581\end{array}$} & \multirow{2}{*}{$\begin{array}{l}\text { Prob } \\
0.000\end{array}$} \\
\hline 1 & 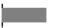 & 1 & 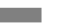 & 1 & 0.501 & & & \\
\hline i & $\square$ & 1 & & 2 & 0.311 & 0.080 & 17.547 & 0.000 \\
\hline 1 & 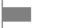 & 1 & & 3 & 0.315 & 0.176 & 22.744 & 0.000 \\
\hline 1 & 0 & $1=$ & & 4 & 0.324 & 0.132 & 28.378 & 0.000 \\
\hline 1 & 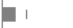 & 10 & & 5 & 0.149 & -0.128 & 29.597 & 0.000 \\
\hline 1 & e 1 & 1 & & 6 & 0.154 & 0.076 & 30.929 & 0.000 \\
\hline 11 & & $1 \mathbf{0}$ & & 7 & 0.044 & -0.154 & 31.042 & 0.000 \\
\hline 11 & 11 & 17 & 1 & 8 & 0.040 & 0.030 & 31.135 & 0.000 \\
\hline 1 & 1 & & 1 & 9 & 0.024 & 0.001 & 31.168 & 0.000 \\
\hline 11 & 1 & 11 & 1 & 10 & 0.022 & -0.005 & 31.199 & 0.001 \\
\hline 11 & 11 & 1 & 1 & 11 & 0.028 & 0.080 & 31.249 & 0.001 \\
\hline & 11 & 1 & 1 & 12 & 0.002 & -0.069 & 31.249 & 0.002 \\
\hline 1 & 1 & 1 C & 1 & 13 & -0.105 & -0.118 & 31.990 & 0.002 \\
\hline 10 & 1 & 10 & 1 & 14 & -0.158 & -0.124 & 33.740 & 0.002 \\
\hline 1 & 1 & 11 & 11 & 15 & -0.087 & 0.039 & 34.289 & 0.003 \\
\hline 1 . & 1 & 11 & 1 & 16 & -0.096 & -0.012 & 34.974 & 0.004 \\
\hline 1 = & 1 & 11 & 1 & 17 & -0.151 & -0.038 & 36.717 & 0.004 \\
\hline 1 & 1 & 1 & 1 & 18 & -0.203 & -0.082 & 39.990 & 0.002 \\
\hline 1 & 1 & 1 & & 19 & -0.084 & 0.105 & 40.571 & 0.003 \\
\hline $1=$ & 1 & 1 뭉 & 1 & 20 & -0.142 & -0.118 & 42.288 & 0.003 \\
\hline
\end{tabular}


Table 1: Regression Results from Estimation of Logarithmic Raw (Level) Models 1960-2007 Annual Data

\begin{tabular}{|c|c|c|c|c|c|c|}
\hline \multirow{3}{*}{$\begin{array}{l}\text { Parameter Estimate } \\
\text { (Std. Error) }\end{array}$} & \multicolumn{6}{|c|}{ Most General Model in Eq. 3} \\
\hline & \multicolumn{3}{|c|}{ Dependent Variable LGMCE\$BN } & \multicolumn{3}{|c|}{ Dependent Variable LGIRS\$BN } \\
\hline & $\underline{\mathrm{OLS}}$ & $\underline{A R 1}$ & $\underline{A R 2}$ & $\underline{\text { OLS }}$ & $\underline{\mathrm{AR} 1}$ & $\underline{A R 2}$ \\
\hline \multirow[t]{2}{*}{$\alpha$} & $-7.895 * * *$ & $* \quad-9.208 * * *$ & k $-10.031 * * *$ & $-7.792 * * *$ & $-9.558 * * *$ & -9.622 \\
\hline & $(0.666)$ & $(1.005)$ & (1.097) & $(0.539)$ & $(1.186)$ & $(1.131)$ \\
\hline \multirow[t]{2}{*}{$\beta_{1}$} & $0.857^{* * *}$ & $1.130 * * *$ & $1.275^{* * *}$ & $0.782 * * *$ & $1.097 * * *$ & $1.108 * * *$ \\
\hline & $(0.108)$ & $(0.152)$ & $(0.170)$ & $(0.087)$ & $(0.150)$ & $(0.169)$ \\
\hline \multirow[t]{2}{*}{$\beta_{2}$} & $1.178^{* * *}$ & $0.881 * * *$ & $0.755 * * *$ & $1.313^{* * *}$ & $1.031 * * *$ & $1.023 * * *$ \\
\hline & $(0.083)$ & $(0.128)$ & $(0.167)$ & $(0.067)$ & $(0.139)$ & $(0.167)$ \\
\hline \multirow[t]{2}{*}{$\rho_{1}$} & $\mathrm{n} / \mathrm{a}$ & $0.939 * * *$ & $1.302 * * *$ & $\mathrm{n} / \mathrm{a}$ & $0.931 * * *$ & $1.257 * * *$ \\
\hline & & $(0.046)$ & $(0.184)$ & & $(0.056)$ & $(0.251)$ \\
\hline \multirow[t]{2}{*}{$\rho_{2}$} & $\mathrm{n} / \mathrm{a}$ & $\mathrm{n} / \mathrm{a}$ & $-0.363 *$ & $\mathrm{n} / \mathrm{a}$ & $\mathrm{n} / \mathrm{a}$ & -0.341 \\
\hline & & & $(0.183)$ & & & $(0.238)$ \\
\hline $\mathrm{R}^{2}$ & 0.995 & 0.999 & 0.999 & 0.997 & 0.999 & 0.999 \\
\hline SSR & 0.261 & 0.046 & 0.041 & 0.171 & 0.032 & 0.028 \\
\hline DW & 0.201 & 1.392 & 2.194 & 0.227 & 1.286 & 1.941 \\
\hline \multicolumn{7}{|l|}{$\mathrm{p}$-value of $\mathrm{H}_{\mathrm{o}}$ : } \\
\hline \multirow[t]{2}{*}{$\beta_{1}=\beta_{2}=\beta$} & $0.0967^{*}$ & 0.3564 & 0.1104 & $0.0012 * * *$ & 0.7972 & 0.7885 \\
\hline & \multicolumn{5}{|c|}{ Restricted Model in Eq. 5} & \\
\hline$\alpha$ & $-4.214 * * *$ & $-3.873 * * *$ & $-3.915 * * *$ & $-4.631 * * *$ & $-4.470 * * *$ & - \\
\hline \multirow[t]{2}{*}{$4.476^{* * *}$} & & & & & & \\
\hline & $(0.089)$ & $(0.310)$ & $(0.296)$ & $(0.079)$ & $(0.596)$ & $(0.460)$ \\
\hline \multirow[t]{2}{*}{$\beta$} & $1.039 * * *$ & $0.998 * * *$ & $1.003 * * *$ & $1.083^{* * *}$ & $1.061 * * *$ & $1.063 * * *$ \\
\hline & $(0.011)$ & $(0.037)$ & $(0.036)$ & $(0.010)$ & $(0.066)$ & $(0.053)$ \\
\hline \multirow[t]{2}{*}{$\rho_{1}$} & $\mathrm{n} / \mathrm{a}$ & $0.926 * * *$ & $1.202 * * *$ & $\mathrm{n} / \mathrm{a}$ & $0.926 * * *$ & $1.248 * * *$ \\
\hline & & $(0.044)$ & $(0.162)$ & & $(0.058)$ & $(0.237)$ \\
\hline \multirow[t]{2}{*}{$\rho_{2}$} & $\mathrm{n} / \mathrm{a}$ & $\mathrm{n} / \mathrm{a}$ & -0.293 & $\mathrm{n} / \mathrm{a}$ & $\mathrm{n} / \mathrm{a}$ & -0.340 \\
\hline & & & $(0.178)$ & & & $(0.230)$ \\
\hline $\mathrm{R}^{2}$ & 0.995 & 0.999 & 0.999 & 0.996 & 0.999 & 0.999 \\
\hline SSR & 0.278 & 0.047 & 0.043 & 0.217 & 0.032 & 0.029 \\
\hline DW & 0.174 & 1.443 & 2.083 & 0.152 & 1.289 & 1.929 \\
\hline \multicolumn{7}{|l|}{$p$-value of } \\
\hline$H_{0}: \beta=1$ & 0.0008 & 0.9539 & 0.9404 & $<0.0001$ & 0.3579 & 0.2477 \\
\hline \multicolumn{7}{|c|}{$\begin{array}{l}\text { Notes: Standard errors in parentheses. n/a means "not applicable". SSR is sum of squared } \\
\text { residuals. }\end{array}$} \\
\hline
\end{tabular}


Table 2: Regression Results from Estimation of First-Differenced Logarithmic Models 1960-2007 Annual Data

Most General Model -- Eq. 3'

Parameter Estimate Dependent Variable D(LGMCE\$BN) Dependent Variable D(LGIRS\$BBN)

\begin{tabular}{|c|c|c|c|c|c|c|}
\hline (Std. Error) & $\underline{\text { OLS }}$ & AR1 & AR2 & $\underline{\text { OLS }}$ & $\underline{A R 1}$ & $\underline{A R 2}$ \\
\hline \multirow[t]{2}{*}{$\delta$} & $-0.037 * *$ & $-0.033 * *$ & $-\overline{0.028}$ & $-0 . \overline{030} * *$ & $-\overline{0.025} *$ & $-0 . \overline{026}$ \\
\hline & $(0.014)$ & $(0.015)$ & (0.019) & $(0.012)$ & $(0.013)$ & $(0.018)$ \\
\hline \multirow[t]{2}{*}{$\beta_{1}$} & $1.690 * * *$ & $1.645^{* * *}$ & $1.657 * * *$ & $1.566 * * *$ & $1.471 * * *$ & $1.511 * * *$ \\
\hline & (0.249) & $(0.176)$ & (0.195) & (0.208) & (0.174) & (0.238) \\
\hline \multirow[t]{2}{*}{$\beta_{2}$} & $1.305^{* * *}$ & $1.224 * * *$ & $1.035 * *$ & $1.378 * * *$ & $1.326 * * *$ & $1.314 * * *$ \\
\hline & $(0.217)$ & $(0.340)$ & $(0.446)$ & $(0.182)$ & $(0.269)$ & $(0.340)$ \\
\hline \multirow[t]{2}{*}{$\rho_{1}$} & $\mathrm{n} / \mathrm{a}$ & 0.217 & 0.198 & $n / a$ & 0.192 & 0.148 \\
\hline & & $(0.187)$ & $(0.233)$ & & $(0.233)$ & $(0.203)$ \\
\hline \multirow[t]{2}{*}{$\rho_{2}$} & $\mathrm{n} / \mathrm{a}$ & $\mathrm{n} / \mathrm{a}$ & 0.288 & $\mathrm{n} / \mathrm{a}$ & $\mathrm{n} / \mathrm{a}$ & 0.155 \\
\hline & & & $(0.228)$ & & & $(0.235)$ \\
\hline $\mathrm{R}^{2}$ & 0.575 & 0.594 & 0.623 & 0.651 & 0.662 & 0.670 \\
\hline SSR & 0.041 & 0.039 & 0.036 & 0.029 & 0.028 & 0.026 \\
\hline DW & 1.555 & 2.049 & 1.963 & 1.632 & 1.980 & 1.957 \\
\hline \multicolumn{7}{|l|}{-value of $\mathrm{H}_{\mathrm{O}}$ : } \\
\hline${ }_{1}=\beta_{2}=\beta$ in Eq. $3^{\prime}$ & 0.1438 & 0.2373 & 0.1476 & 0.3890 & 0.6326 & 0.5403 \\
\hline
\end{tabular}

Restricted Models --Eq. 5' and Eq. 6'

$\begin{array}{lllllll}\delta & -0.035^{* *} & -0.034^{* * *} & -0.037^{* *} & -0.029 * * & -0.025^{* *} & -0.027 \\ & (0.014) & (0.012) & (0.014) & (0.012) & (0.011) & (0.016) \\ \beta & & & & & & \\ & 1.455^{* * *} & 1.446 * * * & 1.484 * * * & 1.451^{* * *} & 1.395^{* * *} & 1.423 * * * \\ & (0.195) & (0.171) & (0.208) & (0.160) & (0.159) & (0.248)\end{array}$

$\begin{array}{ccccccc}\rho_{1} & \mathrm{n} / \mathrm{a} & 0.211 & 0.175 & \mathrm{n} / \mathrm{a} & 0.208 & 0.170 \\ & & (0.168) & (0.190) & & (0.228) & (0.203)\end{array}$

$\begin{array}{lllllll}\rho_{2} & \mathrm{n} / \mathrm{a} & \mathrm{n} / \mathrm{a} & 0.182 & \mathrm{n} / \mathrm{a} & \mathrm{n} / \mathrm{a} & 0.128\end{array}$

$\begin{array}{llll}0.224) & (0.247)\end{array}$

$\begin{array}{lllllll}R^{2} & 0.544 & 0.574 & 0.588 & 0.645 & 0.660 & 0.665\end{array}$

$\begin{array}{lllllll}\text { SSR } & 0.043 & 0.041 & 0.039 & 0.029 & 0.028 & 0.027\end{array}$

$\begin{array}{lllllll}\text { DW } & 1.542 & 2.024 & 1.941 & 1.574 & 1.971 & 1.946\end{array}$

$\begin{array}{lllllll}p \text {-value of } \mathrm{H}_{0}: & & & & & & \\ \beta=1 \text { in Eq. } 5^{\prime} & 0.0239 * * & 0.0125^{* *} & 0.0248 * * & 0.0073 * * * & 0.0168 * * & 0.0948 *\end{array}$

$\begin{array}{lllllll}\delta=0 \text { in Eq. } 6^{\prime} & 0.5573 & 0.5881 & 0.5835 & 0.5449 & 0.7943 & 0.8101\end{array}$

Notes: Standard errors in parentheses. n/a means "not applicable". SSR is sum of squared residuals.

$* * *, * *$ and $*$ denote statistical significance at $p$-values of $0.01,0.05$ and 0.10 , respectively. 
Table 3: Regression Results from Estimation of First-Differenced Logarithmic Models 1981-2007 and 1981-2018 MG8\$BN Annual Data Most General Model -- Eq. 3' - Dependent Variable D(LOGMG8\$BN)

Parameter Estimate

(Std. Error) $\delta$

$\beta_{1}$

$\beta_{2}$

$\rho_{1}$

$\rho_{2}$

$\mathrm{R}^{2}$

SSR

DW

p-value of $\mathrm{H}_{\mathrm{o}}$ :

$\beta_{1}=\beta_{2}=\beta$ in Eq. $3^{\prime}$

Chow - 2000 break

$\delta$

$\beta$

$\rho_{1}$

$\rho_{2}$

$\mathrm{R}^{2}$

SSR

DW

p-value of $\mathrm{H}_{0}$ :

$\beta=1$ in Eq. $5^{\prime}$

Chow -2000 break

1981-2007 Annual Data

$\frac{\text { OLS }}{-0.034} * \quad \frac{\text { AR1 }}{-0.015} \quad \underline{-0.014}$

(0.019)

(0.040)

(0.038)

$1.910^{* * *}$

$1.626 * * *$

$1.617^{* * *}$

(0.372)

(0.309)

(0.307)

0.815

(1.378)

0.800

(1.324)

$(0.360)$

$(0.335)$

(0.393)

$0.356 \quad 0.355$

(0.235)

(0.248)

$\mathrm{n} / \mathrm{a}$

0.050

(0.210)

0.049

$\mathrm{n} / \mathrm{a}$

$$
0.018
$$

(0.324)

$\mathrm{n} / \mathrm{a}$

$\mathrm{n} / \mathrm{a}$

$-0.030$

(0.223)

\subsection{6}

0.022

1.490

0.586

0.020

0.586

0.020

0.686

0.037

1.928

1.871

0.4879

$0.0255^{* *} \quad 0.0056 * * * \quad .0048^{* * *}$

0.1280

0.5052

$0.0005^{* * *}<0.001$
- -Eq. $5^{\prime}$ and Eq. 6

0.687

0.037

0.687

1.941

\subsection{9}

\section{Restricted Models --Eq. 5' and Eq. 6'}

$\begin{array}{lllll}-0.023 & -0.023 & -0.056^{* * *} & -0.054^{* * *} & -0.053^{* * *} \\ (0.016) & (0.016) & (0.014) & (0.010) & (0.010)\end{array}$

(0.020)

$1.359 * * * \quad 1.369 * * *$

(0.292)

(0.289)

$1.965 * * *$

$1.919 * * *$

$1.903^{* * *}$

(0.316)

$0.329 \quad 0.338$

$\mathrm{n} / \mathrm{a}$

0.162 )

(0.164)

$(0.247)$

(0.245)

0.111

0.102

(0.166)

(0.166)

$\mathrm{n} / \mathrm{a} \quad-0.031$

(0.326)

$\mathrm{n} / \mathrm{a}$

$$
\mathrm{n} / \mathrm{a}
$$

0.056

$0.543 \quad 0.544$

0.637

0.043

1.684

1.915

0.022

1.941

0.2322

0.2149

$0.0004^{* * *}<0.0001^{* * *}<0.0001^{* * *}$ $0.0212 * * * \quad 0.0070 * * * .0017 * * *$ Notes: Standard errors in parentheses. n/a means "not applicable". SSR is sum of squared residuals.

$* * *, * *$ and $*$ denote statistical significance at $p$-values of $0.01,0.05$ and 0.10 , respectively. 
Appendix Table 1

Definitions of Sectors Comprising the Advertising and Marketing Services (A\&MS) Industry Based on the North American Industry Classification System ((NAICS)

\begin{tabular}{|c|c|}
\hline NAICS Category & Definition $^{1}$ \\
\hline $\begin{array}{l}541810 \\
\text { Advertising } \\
\text { Agencies }\end{array}$ & $\begin{array}{l}\text { Create advertising campaigns and place such advertisements in media; } \\
\text { organized to provide a full range of services (through in-house capabilities } \\
\text { or subcontracting). }\end{array}$ \\
\hline $\begin{array}{l}541820 \\
\text { Public Relations } \\
\text { Agencies }\end{array}$ & $\begin{array}{l}\text { Design and implement public relations campaigns to promote the interests } \\
\text { and image } \\
\text { of clients; includes establishments providing lobbying and political } \\
\text { consulting services. }\end{array}$ \\
\hline $\begin{array}{l}41830 \\
\text { Media Buying }\end{array}$ & $\begin{array}{l}\text { Purchase advertising time or space from media outlets and reselling it to } \\
\text { advertising agencies or individual companies directly. }\end{array}$ \\
\hline $\begin{array}{l}541850 \\
\text { Outdoor } \\
\text { Advertising }\end{array}$ & $\begin{array}{l}\text { Crete and design public display advertising campaign materials, such as } \\
\text { printed. painted, or electronic displays; and/or placing such displays on } \\
\text { indoor or outdoor billboards and panels, or on or within transit vehicles or } \\
\text { facilities, shopping malls, retail (in-store) displays, and other structures } \\
\text { and sites. }\end{array}$ \\
\hline $\begin{array}{l}541860 \\
\text { Direct Mail } \\
\text { Advertising }\end{array}$ & $\begin{array}{l}\text { Create and design advertising campaigns involving the distributions of } \\
\text { advertising materials (e.g., coupons, flyers, samples) or specialties (e.g., key } \\
\text { chains, magnets, pens); and/or preparing advertising materials and } \\
\text { specialties mailing or other direct distribution; may also compile, maintain, } \\
\text { sell, and rent mailing lists. }\end{array}$ \\
\hline $\begin{array}{l}541870 \\
\text { Advertising } \\
\text { Materials } \\
\text { Distribution }\end{array}$ & $\begin{array}{l}\text { Direct distribution or delivery of advertisements (e.g., circulars, coupons, } \\
\text { handbills) or samples; including door-to-door delivery, placement on car } \\
\text { windshields in parking lots, handouts in retail outlets. }\end{array}$ \\
\hline $\begin{array}{l}541890 \\
\text { Other Services }\end{array}$ & $\begin{array}{l}\text { Includes display and sign lettering, decorating and store window dressing, } \\
\text { welcoming services, merchandise demonstrations. }\end{array}$ \\
\hline $\begin{array}{l}541910 \\
\text { Marketing } \\
\text { Research \& } \\
\text { Public Opinion } \\
\text { Polling }\end{array}$ & $\begin{array}{l}\text { Systematic gathering, recording, tabulating, and presenting marketing and } \\
\text { public opinion data. }\end{array}$ \\
\hline $\begin{array}{l}541613 \\
\text { Marketing } \\
\text { Consulting }\end{array}$ & $\begin{array}{l}\text { Provide operating advice and assistance to businesses and other } \\
\text { organizations on marketing issues, such as developing marketing } \\
\text { objectives, strategies, policies, and plans; sales forecasting, new product } \\
\text { development, pricing, licensing, and franchising. }\end{array}$ \\
\hline
\end{tabular}




\section{Appendix Table 2a}

Summary Statistics for Annual Advertising

Expenditure and GDP Time Series: Median and Range

\begin{tabular}{|c|c|c|c|c|c|}
\hline & & & Period & & \\
\hline $\begin{array}{l}\text { Variable } \\
\text { (\$Bill.) }\end{array}$ & $\begin{array}{l}1960- \\
2007\end{array}$ & $\begin{array}{l}1960- \\
2014\end{array}$ & $\begin{array}{l}1980- \\
2018\end{array}$ & $\begin{array}{l}1996- \\
2018\end{array}$ & $\begin{array}{c}1960- \\
2018\end{array}$ \\
\hline $\begin{array}{l}\text { MCE } \\
\text { Median } \\
\text { (Range) }\end{array}$ & $\begin{array}{l}82.005 \\
(11.860- \\
281.653)\end{array}$ & & & & \\
\hline $\begin{array}{l}\text { IRS } \\
\text { Median } \\
\text { (Range) }\end{array}$ & & $\begin{array}{l}106.556 \\
(9.291- \\
295.421)\end{array}$ & & & \\
\hline $\begin{array}{l}\text { MG8 } \\
\text { Median } \\
\text { (Range) }\end{array}$ & & & $\begin{array}{l}162.739 \\
(41.021- \\
232.906)\end{array}$ & & \\
\hline $\begin{array}{l}\text { SAS6 } \\
\text { Median } \\
\text { (Range) }\end{array}$ & & & & $\begin{array}{c}79.027 \\
(44.519- \\
112.129\end{array}$ & \\
\hline $\begin{array}{l}\text { GDP } \\
\text { Nominal } \\
\text { Median } \\
\text { (Range) }\end{array}$ & & & & & $\begin{array}{l}564.1 .600 \\
(542.400- \\
20580.20)\end{array}$ \\
\hline $\begin{array}{l}\text { GDO } \\
\text { Real } \\
\text { Median } \\
\text { (Range) }\end{array}$ & & & & & $\begin{array}{l}9192.166 \\
(3260.007- \\
188638.11)\end{array}$ \\
\hline $\begin{array}{l}\text { GDPIPD } \\
\text { Median } \\
\text { (Range) } \\
2012= \\
100\end{array}$ & & & & & $\begin{array}{c}61.374 \\
(16.6380- \\
110.420)\end{array}$ \\
\hline
\end{tabular}




\section{Appendix Table $2 b$}

Summary Statistics for Annual Advertising Expenditure and GDP Time Series:

Mean and Std. Dev. (\$Billion)

\begin{tabular}{|c|c|c|c|c|c|}
\hline & & & Period & & \\
\hline $\begin{array}{l}\text { Variable } \\
\text { (\$Bill.) }\end{array}$ & $\begin{array}{l}1960- \\
2007\end{array}$ & $\begin{array}{l}1960- \\
2014\end{array}$ & $\begin{array}{l}1980- \\
2018\end{array}$ & $\begin{array}{l}1996- \\
2018\end{array}$ & $\begin{array}{r}1960- \\
2018 \\
\end{array}$ \\
\hline $\begin{array}{c}\text { MCE } \\
\text { Mean } \\
\text { (Std. Dev.) }\end{array}$ & $\begin{array}{r}104.982 \\
(89.494)\end{array}$ & & & & \\
\hline $\begin{array}{c}\text { IRS } \\
\text { Mean } \\
\text { (Std. Dev.) }\end{array}$ & & $\begin{array}{l}122.399 \\
(98.494)\end{array}$ & & & \\
\hline $\begin{array}{c}\text { MG8 } \\
\text { Mean } \\
\text { (Std. Dev.) }\end{array}$ & & & $\begin{array}{l}140.142 \\
(56.598\end{array}$ & & \\
\hline $\begin{array}{l}\text { SAS6 } \\
\text { Mean } \\
\text { (Std. Dev.) }\end{array}$ & & & & $\begin{array}{l}75.938 \\
(18.839)\end{array}$ & \\
\hline $\begin{array}{l}\text { GDP } \\
\text { Nominal } \\
\text { Mean } \\
\text { (Std. Dev.) }\end{array}$ & & & & & $\begin{array}{l}7220.281 \\
(6085.592)\end{array}$ \\
\hline $\begin{array}{l}\text { GDP } \\
\text { Real } \\
\text { Mean } \\
\text { (Std. Dev.) }\end{array}$ & & & & & $\begin{array}{c}9845.972 \\
(4666.481)\end{array}$ \\
\hline $\begin{array}{c}\text { GDPIPD } \\
\text { Mean } \\
\text { (Std. Dev.) } \\
2012= \\
100\end{array}$ & & & & & $\begin{array}{c}59.335 \\
(30.505)\end{array}$ \\
\hline
\end{tabular}


Appendix Table 3

Summary Statistics for Two Composite Advertising Price Indices, PPI for Finished Goods, and GDP Implicit Price Deflator: 1960-2006 ( $n=47)$

\begin{tabular}{|c|c|c|c|c|}
\hline & CNLCPM & CNTCPM & PPIFGA & GDPIPDA \\
\hline Mean & 113.585 & 120.734 & 87.352 & 95.509 \\
\hline Std. Dev. & 75.828 & 87.426 & 41.362 & 48.047 \\
\hline Median & 99.000 & 99.000 & 98.929 & 100.054 \\
\hline Minimum & 29.000 & 31.000 & 32.522 & 32.605 \\
\hline Maximum & 261.800 & 299.900 & 156.183 & 176.501 \\
\hline $\mathrm{n}$ & 47 & 47 & 47 & 47 \\
\hline
\end{tabular}

CNLCPM = MCE Composite Index National \& Local Budgets, 1982-84=100

CNTCPM = MCE Composite Index for National Budgets Only (excluding Direct Mail), 1982-

$84=100$

PPIFGA $=$ Producers Price Index for Finished Goods, 1982-84=100

GDPIPDA = GDP Implicit Price Deflator, 1982-84=100

Pairwise Correlations Among: CNLCPM, CNTCPM, PPIFGA, and GDPIPDA

\begin{tabular}{|l|l|c|l|l|}
\hline & CNLCPM & CNTCPM & PPIFGA & GDPIPDA \\
\hline CNLCPM & ------- & & & \\
\hline CNTCPM & 0.996 & -------- & & \\
\hline PPIFGA & 0.962 & 0.938 & ------ & \\
\hline GDPIPDA & 0.981 & 0.961 & 0.995 & ------- \\
\hline
\end{tabular}




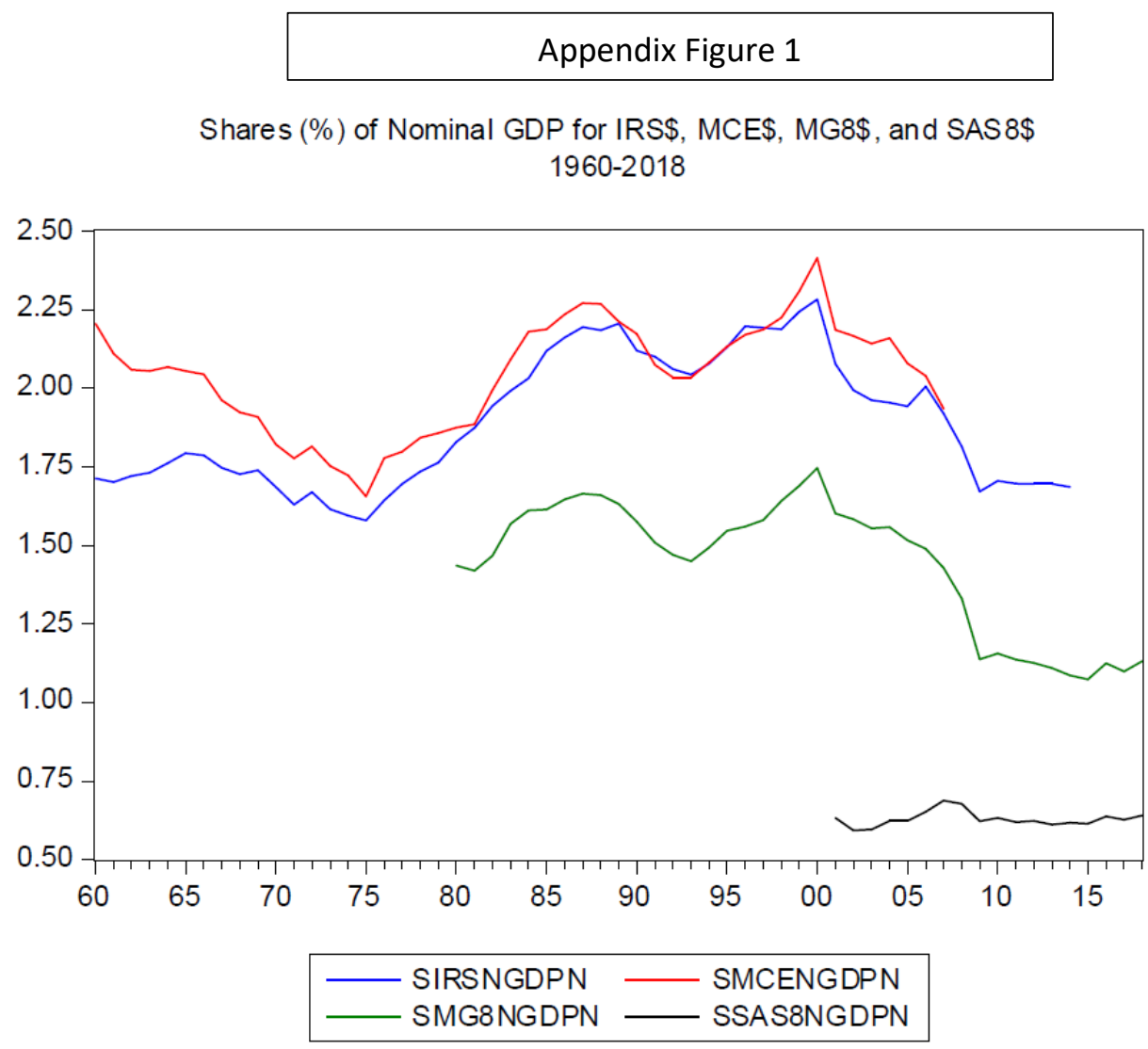


Appendix Figure 2

Annual Nominal Growth Rates in U.S. Advertising Expenditures and GDP: $1960-201 \varepsilon$ (\% Changes)

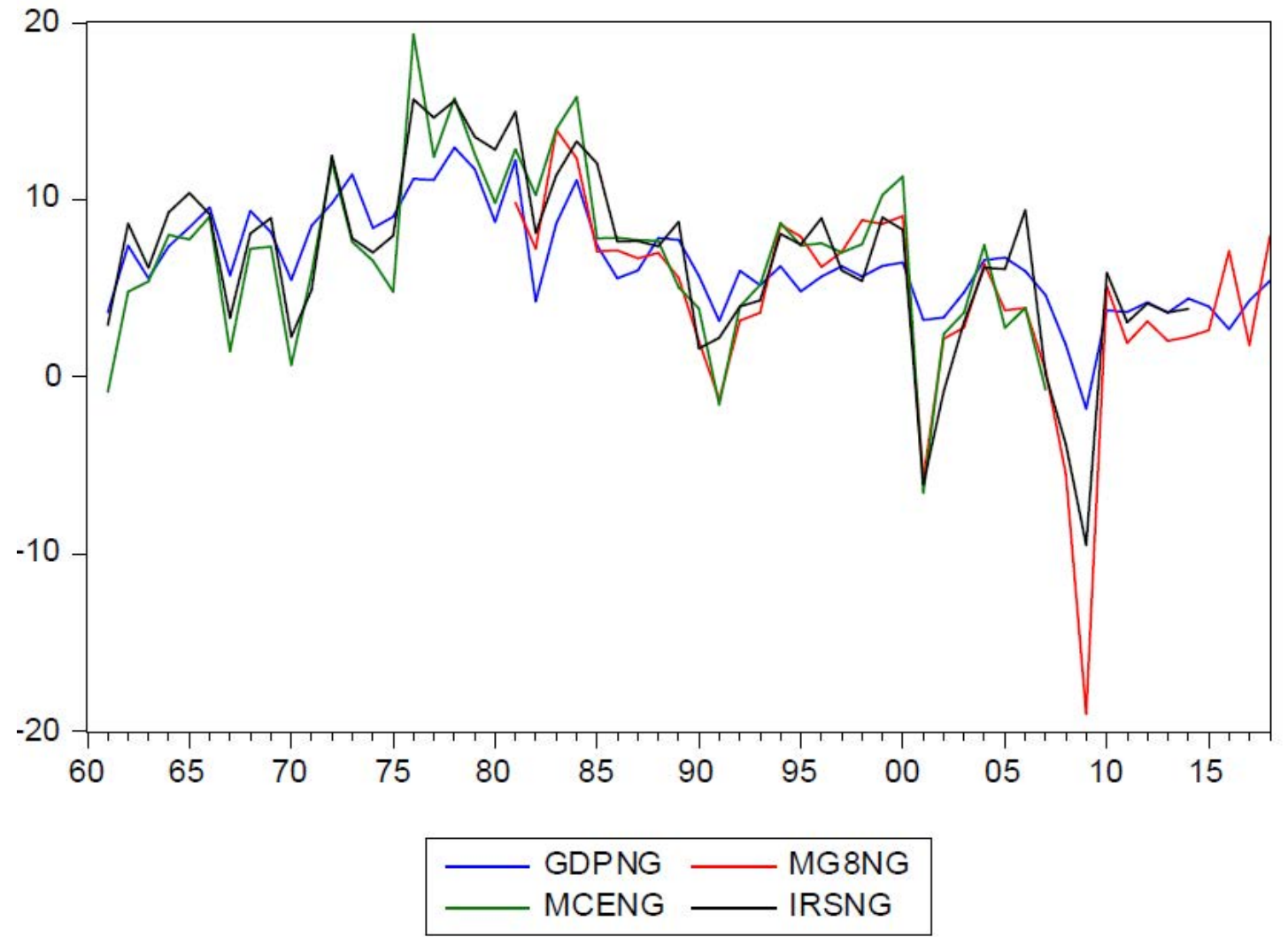


Appendix Figure 3

Shares (\%) of Nominal Private Sector GDP for IRS\$, MCE\$, MG8\$, and SAS8\$: 1980-2018

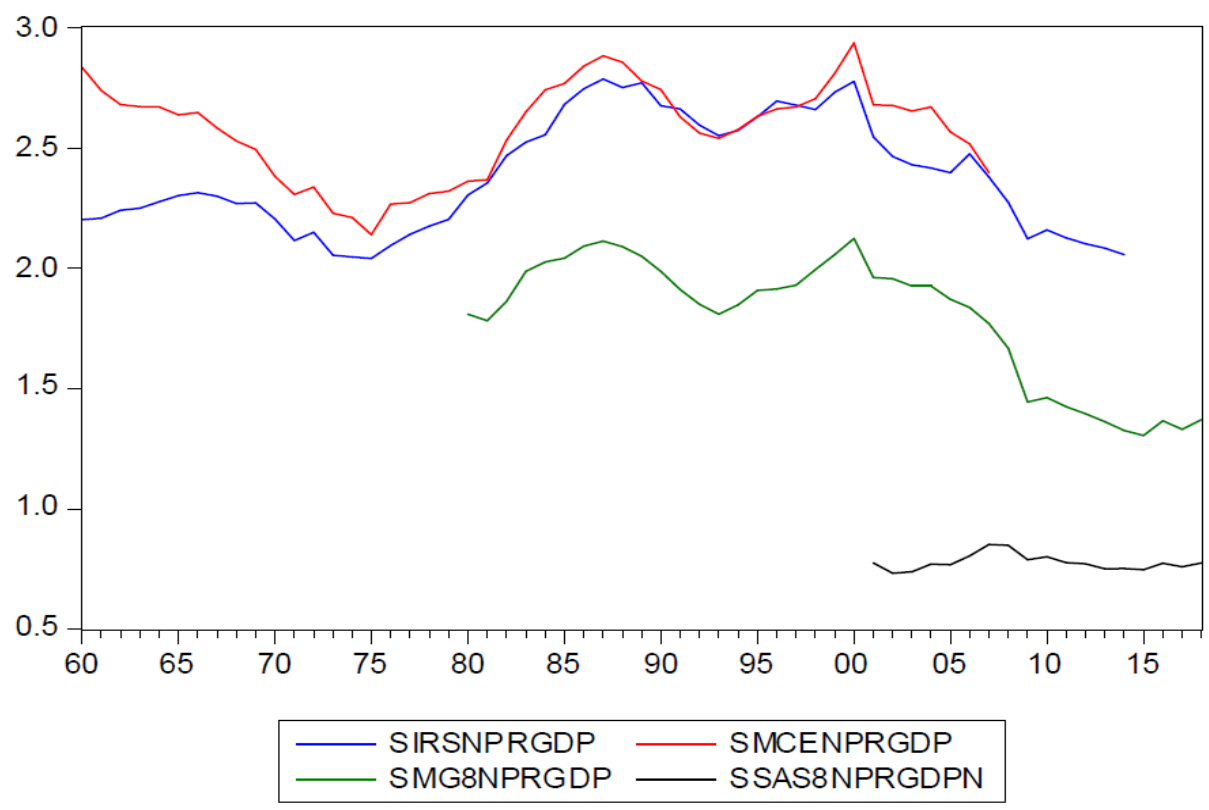

